\title{
LA CAPILLA DE MÚSICA DE LA CATEDRAL DE SEGORBE EN EL SIGLO XVIII
}

\author{
Paulino CAPDEPÓN VERdú
}

\begin{abstract}
Near the cathedrals of Valencia and Orihuela and the Valencia Seminario del Corpus Christi, the Segorbe Cathedral constitutes one of the principal músical centers of the Comundad Valenciana. In this article is studied as introduction the origin of the diocese, his difficulties to be seated and finally, his administrative structure and the principal ecclesiastic charges.

After this introduction, is analyzed the musical activity of the chapel masters that exercised this function in the cathedral of Segorbe during the 18th century (Mateo Peñalba, Onofre Molina, José Conejos Ortells, José Gil Pérez, Francisco Vives, Vicente Olmos, José Gavaldá, Joaquín López, José Morata and José Gil). It stands up the importance of Valencia as training center for the Segorbe musicians, and in some cases as final objective of their professional career. Our article is based in different documentation preserved in the Cathedral; however some documentation was lost during the Spanish Civil War.
\end{abstract}

\section{Resumen}

Junto a las catedrales de Valencia y Orihuela y el Seminario del Corpus Christi de Valencia, la Catedral de Segorbe constituye uno de los principales centros musicales de la Comunidad Valenciana. En este artículo se estudia a modo de introducción el origen de la diócesis, sus dificultades para asentarse y por último, su estructura administrativa y los principales cargos eclesiásticos. Tras esta introducción, se analiza la actividad musical de los maestros que ejercieron el magisterio de capilla en dicha catedral durante el siglo xviII (Mateo Peñalba, Onofre Molina, José Conejos Ortells, José Gil Pérez, Francisco Vives, Vicente Olmos, José Gavaldá, Joaquín López, José Morata y José Gil). Destaca la importancia de Valencia como centro de formación para los músicos de Segorbe, y en algunos casos como objetivo final de su carrera profesional. Para ello nos basamos en diferente documentación conservada en la Catedral, que sin embargo ofrece algunas lagunas ya que parte de las actas capitulares se perdieron durante la Guerra Civil española.

\section{Introducción}

El origen de la diócesis de Segorbe-Albarracín data de la época de la Reconquista a consecuencia de las aspiraciones de independencia política del señorío de Albarracín y de las ambiciones jurisdiccionales del arzobispo de Toledo, de quien depende. Para Blasco Aguilar, «pocas iglesias [Segorbe-Albarracín] habrán tenido que luchar como ésta por conseguir un mínimo y descabellado territorio que nadie le reconocía. Sólo el hecho de existir le daba alguna esperanza de consolidarse algún día a costa de sus convecinas Valencia y Tortosa... Para garantizar su pervivencia se había decretado la unión perpetua de Segorbe y Albarracín, original fórmula jurídi- 
ca que dio como resultado un no menos original cabildo con residencia y coro precarios en dos catedrales enormemente distantes». ${ }^{1}$

Mansilla destaca que la existencia del obispado de Segorbe-Albarracín estuvo en peligro a comienzos del siglo XIV cuando se planteó la división de la provincia tarraconense y se llevó a efecto la erección de la metrópoli de Zaragoza. El 22 de noviembre de 1317 hubo una propuesta del rey Jaime II al papa Juan XXII en el sentido de trasladar la sede de Albarracín a Teruel, que constituía uno de los nuevos obispados de nueva creación. De esta manera el rey de Aragón quería anular toda injerencia en su reino, y en este caso del arzobispado de Toledo, de quien dependía el obispado de Segorbe-Abarracín, como vimos anteriormente. Dicho rey logró parcialmente lo que se propuso ya que a partir del 14 de agosto de 1318, el obispado de Albarracín pasó a depender eclesiásticamente de Zaragoza. ${ }^{2}$

De toda maneras existían desde el principio dos vicariatos con su respectiva curia y jurisdicción territorial, como forma de lograr una buena administración y gobierno. El cabildo, por su parte, si bien era unitario, tenía residencia y coro en las dos catedrales, distinguiéndose con claridad las rentas y prebendas de una y otra, todo lo cual llevaba en sí el germen de la separación, la cual tendrá lugar con motivo de la reorganización eclesiástica acometida por el rey Felipe II en el siglo XVI, siendo las razones de orden administrativo y de buen gobierno. Pero además — siguiendo a Blasco Aguilar-, había otras motivaciones para la desmembración, entre ellas el problema de la conversión de los moriscos, muy presentes en la zona de Segorbe, así como el abandono en que se tenía la iglesia de Albarracín, tanto por parte del obispo como de los canónigos. La separación se efectuará el 21 de julio de 1577, fecha en que el Papa Gregorio XIII expidió su Bula Regimini, nombrándose a la vez a Francisco Sancho como obispo de Segorbe y a Juan Trullo obispo de Albarracín. ${ }^{3}$

A consecuencia de dicha separación de Segorbe y Albarracín, el Cabildo segorbicense quedó formado por catorce miembros, número que permaneció invariable hasta el Concordato de 1851: Deán, Arcediano Mayor, Tesorero, Arcediano de Alpuente, Teólogo, Doctoral, Penitenciario, Curado y seis canónigos simples.

Entre la canonjías de oficio destacan el Lectoral, Doctoral, Penitenciario y Magistral, que están unidos a una canonjía determinada, y siempre forman parte del cabildo catedral.

Otras canonjías, que no pertenecen al cabildo catedral de Segorbe, fueron creadas por diferentes causas y existieron en alguna etapa de su historia. Son la prepositura, la canonjía de San Jaime, y la canonjía de la Inquisición. Además de las dignidades y canónigos, también hicieron acto de presencia en la catedral de Segorbe otros ministros auxiliares de aquéllos. Dada su gran variedad se les puede clasificar a todos bajo la denominación de beneficiados. En algunas ocasiones, la institución y provisión de los beneficios correspondía al obispo y cabildo que seña-

1. Blasco Aguilar, J.: Historia y Derecho en la Catedral de Segorbe, Caja de Ahorros y Monte de Piedad de Segorbe, Segorbe 1973, pág. 328s. $171 \mathrm{~s}$.

2. Mansilla, D.: «La reorganización eclesiástica española del siglo XVI», Anthologica Annua, vol. IV, 1956, pág.

3. Blasco Aguilar, op. cit., pág. 330ss. 
laban tanto las rentas como las obligaciones de cada uno. En otras, intervenía sólo el cabildo, previa la propuesta del canónigo encargado de supervisar aquel oficio. Aparte de las obligaciones específicas propias - misas, canto, sacristías, etc. - los beneficiados y demás ministros auxiliares «estaban para ayudar en todo lo concerniente al coro y al altar, y, por lo común, ellos solos - particularmente los sacristanes - rezaban los maitines a media noche, hasta que, para corregir este abuso, se trasladaron en 1877 a la tarde anterior con objeto de que pudiera asistir todo el cabildo». ${ }^{4}$

Su residencia personal era controlada y si se ausentaban más de tres días, el maestro de gramática, arte y canto, y el físico o médico, podían incluso perder sus puestos o buena parte de su pensión. En cuanto al aspecto económico, algunos beneficios consistían en las rentas que les asignaba el cabildo, bien procedentes de la masa común antes de hacer el reparto entre los prebendados, bien de algunos otros fondos especiales, como la Administración de la Prepositura; otros, muy numerosos por cierto, poseían su propio patrimonio, a veces pingüe, pero lo habitual es que fueran escasos de rentas. Además de la renta propia, que muchas veces era insignificante, tenían los beneficiados participación en las distribuciones de los aniversarios y doblas.

No se evitó una excesiva multiplicación de los beneficiados, con el consiguiente desorden en su organización, insuficiente dotación en muchos casos y normal abandono de la residencia. Fue por iniciativa del rey Fernando VI que se promovió la reducción de beneficios en la catedral y en las demás iglesias de la diócesis.

Debe destacarse ante todo en este apartado de «Beneficiados» la administración de la Prepositura, que no fue en sí misma un beneficio sino el germen de muchos de ellos y otros cargos. Esta institución mereció la aprobación del papa Clemente VII, concedida en 1389 tanto en favor de la supresión de la prebenda como del nuevo destino dado a las rentas. Con las rentas de la Prepositura se crearon, en primer lugar, los oficios siguientes: Maestro de Gramática y Artes liberales, Maestro de Canto, y Médico del obispo y cabildo y de los pobres.

Asimismo, se volvieron a dotar otros oficios ya existentes: Capellán misalbero, Diaconil, Subdiaconil, Sacristanes y Apuntador. Poco después, entre 1576 y 1577, aprovechando el tiempo de sede vacante, se incluyeron en la nómina de la Administración de la Prepositura cinco nuevos oficios: Organista, Manchador, Pertiguero, $2^{\circ}$ Maestro de Ceremonias y Notario del cabildo. La ampliación fue mayor aún en 1580, año en que el cabildo dotó a cargo de los mismos fondos los oficios siguientes: Otro maestro de ceremonias, Cantor, Ayudante del sacristán, Segundo diaconil, Segundo subdiaconil. Ministro de báculo y Ministro de mitra.

En 1606, el obispo privó al cabildo de la Administración de la Prepositura, quedando deterioradas las relaciones entre ambas partes. Ante la gravedad de la situación, el Papa no dudó en exhortar e incluso reprender al obispo que, por una cuestión de administración, se había enemistado con su cabildo. Ante tal llamada de atención, el obispo y cabildo dejaron a un lado sus diferencias y llegaron a un acuerdo general, por el momento, cantándose, incluso, un solemne Te Deum de acción de gracias por la conciliación. Pero el problema seguía latente, y en 1734 el

4. Ibidem, pág. 170. 


\section{Paulino Capdepón Verdú}

cabildo se incautó de todos los bienes que antiguamente constituyeron la prebenda de la Prepositura, dejando, en consecuencia, sin fondos y sin vida a la Administración.

\section{Maestros de Segorbe en el siglo XviII}

\section{Mateo Peñalba}

La vida del primer maestro de capilla de la catedral de Segorbe en el siglo XVIII no se conoce en profundidad, por lo que ignoramos su fecha de nacimiento y procedencia. Climent afirma que el hecho de que en Onteniente haya otro músico Peñalba Donat, no es motivo para suponer su nacimiento en Onteniente, ni para emparentarlos entre sí. ${ }^{5}$

Peñalba fue nombrado sochantre de la Catedral de Segorbe el día 22 de noviembre de 1681, previo concurso. Cuando el entonces maestro de capilla de Segorbe, Miguel Monchiu Panzano, falleció el 12 de abril de 1684, se le encomendó que ejerciera las funciones de maestro provisional, cargo que desempeñó durante 26 años, conservando su propiedad sobre la Capellanía de sochantre pero cediendo a Pedro Morante, sacabuche de la capilla, las 10 libras que por regir la Capilla le habían sido asignadas. ${ }^{6}$

En vista de su competencia y dedicación el cabildo le nombró maestro con «todos los honores y preeminencias de que han gozado los demás Maestros de Capilla de esta Santa Iglesia», acuerdo tomado el 20 de Febrero de $1691 .^{7}$ Dimitió de su cargo el 9 de mayo de 1710 , quedando sólo con la sochantría hasta el 10 de junio de 1714, año en que murió, ${ }^{8}$ finalizando su trayectoria musical de 33 años en la catedral de Segorbe.

Por otra parte, en el acta capitular del 15 de Noviembre de 1719 se afirma que Vicente Ferrer, cuñado del difunto Peñalba, cede al archivo segorbino la música que tenía del citado maestro, rogando al Cabildo que asistiesen al entierro de su mujer, María Peñalba, todos los músicos de la Capilla. El Cabildo gratificó a los músicos con tres libras. ${ }^{9}$

La única fuente de la obra musical de Peñalba se conserva en la Catedral de Segorbe: 10 salmos, 4 motetes, 1 magnificat, 3 Antífonas, 1 Himno y 60 villancicos. Por su parte, José Perpiñán afirma que se perdieron un total de 24 obras, sin especificar los motivos de tal pérdida. Concretamente se refiere a 3 Misas a 4, 8 y 12, 2 Misereres a 8 y 12, el Motete $O$ quam speciosa a 10, 1 Motete Maria virgo a 11, 11 Villancicos, 1 Lamentación y 5 Salmos de vísperas. ${ }^{10}$

5. Climent, J.: Fondos musicales de la región valenciana: Vol. III (Catedral de Segorbe), Caja de Ahorros y Monte de Piedad de Segorbe, Segorbe 1984, pág. 196.

6. Pedro Morante tenía dos hermanos, José Morante, bajonista, y Jorge Morante, bajonista y tenor; uno y otro poseían en esta Catedral capellanías de ministriles. El $1^{\circ}$ de ellos aparece varias veces actuando de censor en oposiciones. Véase PERPIÑAN, J.: «Cronología de los maestros de capilla y organistas de la Santa Iglesia Catedral de Segorbe», La música religiosa en España, núm. 13, 1897, pág. 201.

7. Véase Apéndice I, Doc. 1.

8. Véase Apéndice I, Doc. 2.

9. Citado en Perpiñan, op. cit., núm. 13, 1897, pág. 204.

10. Ibidem, núm. 14, pág. 219. 


\section{Onofre Molina}

Tras el fallecimiento de Mateo Peñalba, el 16 de marzo de 1715 fue nombrado Onofre Molina con carácter provisional. De este maestro afirma Perpiñán que «se ignora por qué no hubo oposición, a pesar de que Molina, perito y apto, venía desempeñando, mediante oposición la Capellanía de contralto desde enero de 1715 y de que el Cabildo le sobredotó con 25 libras y demás mejoras propias de sus antecesores». ${ }^{11}$ Tales condiciones no debieron convencer a Molina, quien el 26 de marzo de 1716 renunció al magisterio de capilla, por lo que el Cabildo encargó al tenor Antonio Díaz la instrucción de los infantes y para dirigir la capilla a Baltasar Flor, tenor domero y el más antiguo de la Capilla, ambos remunerados con cuatro libras.

De este maestro no se conserva ninguna obra en el archivo catedralicio de Segorbe mientras que en la Catedral Metropolitana de Valencia han llegado hasta nosotros un Magnificat y un Villancico a Santa Teresa.

\section{José Conejos Ortells}

Debido a la renuncia de Onofre Molina en marzo de 1716, tal como veíamos anteriormente, en junio de 1716 el Cabildo segorbino acuerda que se conteste a los pretendientes del magisterio vacante, prometiéndoles 30 libras y las distribuciones anuales como a los restantes beneficiados. Las actas de 1716 no vuelven a hacer mención de este asunto. ${ }^{12}$

El acta capitular del 8 de Noviembre de 1717 menciona ya como maestro a Conejos. Según Perpiñán faltan algunas hojas de las actas, por lo que es de suponer que fue nombrado a principios de $1717 .^{13}$

Las ausencias de los músicos dan lugar a que se consideren sin cubrir el puesto o la capellanía corrrespondiente: así ocurre en 1731 con el contralto y licenciado Ambrosio Gómez, el cual es sustituido por otro contralto, Lorenzo Juan, quien es recomendado por dos músicos de la catedral segorbina. ${ }^{14}$

Cuando los niños o infantes de coro ${ }^{15}$ cambian la voz y ya no pueden cantar en la capilla como tiples, se les sustituye por otros. Esto es lo que le ocurre en 1732 a José Gil. Pero no se trata de un niño de coro cualquiera, sino del que llegará a ser con el tiempo el sucesor del maestro Conejos Ortells, como veremos más adelante: «Por no poder servir ya en la capilla el infante José Gil por razón de haber perdido la voz de tiple, deliberaron dichos señores que en su lugar entre otro infante para el primero de marzo próximo venidero». ${ }^{16}$

11. Ibidem, pág. 219.

12. Ibidem, pág. 219.

13. Ibidem, pág. 220.

14. Véase Apéndice I, Doc. 3.

15. Fueron instituidos por el cabildo en 1419. Reunidos los canónigos comprobaron que los bienes de la Administración de la Prepositura habían ido aumentando en los últimos años, y como en el coro de la catedral no se podían celebrar los divinos oficios, al modo como lo hacían otras iglesias, por carecer de infantillos, decidieron crear dos plazas de niños clérigos que con hábito decente y honesto sirviesen en el coro en todas las horas nocturnas y diurnas. Su elección y destitución sería libremente por el cabildo. Citado en Blasco Agullar, op. cit., pág. 234.

16. ACS, $15-2-1732$. 
Dos semanas más tarde ya se ha efectuado la sustitución. ${ }^{17}$ Sin embargo, dadas las facultades mostradas por José Gil, el Cabildo le permite que siga participando en los ensayos de la capilla: «Asimismo deliberaron que se dé facultad a José Gil, infante que se fue de la Iglesia para que pueda entrar en el coro a ejercitar su voz, sentándose en el escaño de los infantes y con hábito de acólito de coro, sin estipendio alguno». ${ }^{18}$

Ese mismo año de 1732 se celebra la toma de Orán, para lo cual se recompensa a los ministriles: «Señores Deán, Llorens, Vicente Bach, Borrell, Martínez, Sanz Capdevila, deliberaron se les dé a los ministriles a cada uno 10 L[ibras] de las acomodaciones raciones en atención al trabajo que tuvieron de tañer en el campanario en los días 12 y 13 de los corrientes por la toma de Orán». ${ }^{19}$

Una constante en la vida musical de la catedral son los exámenes de los nuevos candidatos a formar parte de la capilla, tal como ocurre con los niños de coro, incluso antes de que queden vacantes, como el siguiente caso:

«Asimismo se dio comisión al señor Don Luis Llorens, [...] de esta Santa Iglesia para que hiciese examinar a José Perpiñán y a Manuel Selma para infantillos de esta Santa Iglesia y los examinadores dieron las voces por buenas y enseguida se admitieron los dos, entrando primero dicho Selma y Perpiñán en la primera vacante que haya». ${ }^{20}$

En la época en que Conejos Ortells rige el magisterio de capilla se consagra la costumbre de nombrar a ciertos miembros del Cabildo para que revisen y aprueben o denieguen los textos de los villancicos, dado el grado de irreverencia religiosa a que se había llegado en determinados casos. Así, el 14 de octubre de 1732 los encargados de esta tarea son el arcediano Martínez y un tal Orellana, sin que sepamos exactamente qué cargo ocupaba este último. ${ }^{21}$

Asimismo son frecuentes las peticiones al Cabildo de la catedral de Segorbe por parte de los músicos para que se les ayude económicamente. Es el caso de Lorenzo Juan, quien había accedido a la capellanía de contralto en 1731, tal como habíamos visto anteriormente, y que dos años después de su ingreso en la capilla se dirige al Cabildo, el cual contesta afirmativamente a su petición. ${ }^{22}$

Al igual que ocurre con los cantantes, las plazas de bajón se adjudican directamente a dos ministriles que llevan trabajando en la catedral desde hacía diez años y no por concurso como era lo habitual. ${ }^{23}$ En la misma reunión capitular del Cabildo se acuerda sin embargo que todas las plazas se adjudiquen en lo sucesivo por concurso. ${ }^{24}$ El problema no acabó de resolverse pues vuel-

17. «Señor Deán, Señor Bach, Señor Cabrera, Señor García, Señor Orellana, Señor Martínez, Señor Oller deliberaron que para los primeros de marzo siguiente se admita por infantillo en lugar de José Gil a Joaquín Pavía». ACS, 20-2-1732.

18. ACS, 15-3-1732.

19. ACS, 22-7-1732.

20. ACS, 13-8-1732.

21. ACS, 14-10-1732.

22. Véase Apéndice I, Doc. 4.

23. Véase Apéndice I, Doc. 5.

24. «Ultimamente deliberaron que en adelante no se pueda proveer ninguna plaza o capellanía de esta Santa Iglesia que no sea por concurso y examen por razón de hallarse constitución jurada en esta Santa Iglesia que lo manda. Se observe en esta conformidad». Ibidem. 
ve a ser tratado al día siguiente: se confirma la primera decisión de admitir a los dos ministriles sin concurso previo a pesar de la oposición del canónigo magistral. Se les pone la condición que además del bajón, tañan el oboe u otro instrumento. De las dos plazas de bajón, una se adscribe al primer coro, por lo que lleva consigo un salario mayor, y otra al segundo coro. Este procedimiento era semejante a los cantores ya que los pertenecientes al primer coro - normalmente se trataba de solistas - tenían mayores emolumentos que los del segundo coro - o «grueso de la capilla». ${ }^{25}$

En 1735 se admite al sochantre Lorenzo Heredia como cantor en sustitución de Vicente Selma, especificándose que aparte de su salario se le concederá la parte correspondiente — «porción»- a las actuaciones en la propia catedral y fuera de ella. En la misma reunión del Cabildo se trata del mal estado del órgano de la catedral debido al deterioro de varios de sus registros. ${ }^{26}$ Un año y medio después de la admisión de Lorenzo Heredia como cantor, éste solicita que se le otorgue la capellanía definitiva, para de esta manera poder ordenarse sacerdote. El Cabildo accede a su petición y le confirma además en la función de sochantre, en sustitución de Vicent Selma. ${ }^{27}$

El asunto de las herencias siempre es motivo de polémica y discordia, tal como puede observarse en el siguiente documento, en el que se exige a Gerónimo Gil que entregue las partituras e instrumentos, que pertenecen a la Catedral, al secretario del Cabildo. ${ }^{28}$

Las cuestiones de disciplina forman parte del devenir diario de la capilla de música y de la Catedral en general. Así, el 1 de enero de 1741 se trata en la reunión del Cabildo el suceso acaecido días antes, en el que el arcediano había advertido que el coro cantaba a excesiva velocidad, a lo que respondió violentamente uno de los cantores, Lorenzo Heredia, quien además insulta a miembros del Cabildo, por lo que se le impone una elevada multa: 101 libras, que se destinarán a los gastos derivados de la restauración del órgano. ${ }^{29}$ Es asimismo habitual que tras la imposición de una multa, se intente por parte del multado condonar o al menos reducir la cantidad. En el caso antes mencionado de Lorenzo Heredia el mismo Obispo interviene para que se le reduzca la multa. ${ }^{30}$

La opinión del Cabildo sobre su maestro de capilla, José Conejos Ortells, fue siempre muy positiva, como lo demuestra el siguiente acuerdo capitular:

«Habiendo suplicado al Ilustre Cabildo mosén Joseph Conejos, Maestro de Capilla, la gracia de que a sus costas se le permitiera iluminar la Capilla de San Miguel y todos Santos, sita en los Claustros de esta Santa Iglesia, a hacer un retablo nuevo, en la testera de dicha capilla para colocar en el centro San Joseph, y San Blas, y en el remate San Miguel, y a los lados todos Santos, cuya invocación tiene dicha Capilla; atendiendo dichos Señores al cristiano celo y devoción del suplicante, como y que por este medio quedaría hermoseada

25. Véase Apéndice I, Doc. 6.

26. Véase Apéndice I, Doc. 7.

27. Véase Apéndice I, Doc. 8.

28. Véase Apéndice I, Doc. 9.

29. Véase Apéndice I, Doc. 10.

30. Véase Apéndice I, Doc. 11. 
dicha capilla, deliberaron se le hiciera dicha gracia, y que por ella se le dieran las gracias». ${ }^{31}$

Como puede verse, la intervención de Conejos Ortells no se limita exclusivamente al ámbito musical. Al asunto antes tratado de la iluminación de una capilla se vuelve a referir el Cabildo diez días después. ${ }^{32}$ En julio de aquel año el Cabildo aborda de nuevo el tema. ${ }^{33}$

A finales de 1741 se renueva la plaza de tenor. Como suele ser común en estas cuestiones, para examinar a los posibles candidatos se nombra al maestro de capilla, José Conejos Ortells, y al domero de la catedral, Joaquín Gómez, que además pertenece a la capilla. Se nombra además a dos miembros del Cabildo para que se hagan cumplir las normas establecidas en el edicto de convocatoria y se respete «la costumbre de esta Santa iglesia» en las oposiciones de la catedral:

«Por el motivo de hallarse vacante la plaza de Sochantre por ausencia de mosén Vicente Fabra se determinó eregir capellanía de Tenor, lo que habiéndose de proveer por concurso, deliberaron dichos Señores fuesen examinadores mosén Joseph Conejos, Maestro de Capilla, y mosén Joaquín Gómez, cuyos exámenes serán el día 16 del presente mes; y asimismo nombraron para asistir en dichos exámenes por parte del ilustre Cabildo a los Señores Don Luis Llorens y Don Juan Bautista Albert». ${ }^{34}$

El resultado de esta oposición se da a conocer diez días después, concretamente el 19 de diciembre de 1741. Son dos los opositores: Miguel Sanz, capiscol de la Iglesia Parroquial de Santa Cruz de Valencia y Joaquín Royo, de quien no se especifica ni la procedencia ni el cargo. El dictamen de los dos examinadores, Conejos Ortells y Gómez, es negativo para ambos, ya que ninguno posee «las cualidades necesarias para el cumplimiento de las obligaciones». El Cabildo acepta el veredicto de sus dos examinadores. ${ }^{35}$

Un conflicto permanente en la vida musical de las catedrales de la España dieciochesca es el interés de los miembros de la capilla por intervenir en fiestas religiosas de otras iglesias o en fiestas de carácter profano, como una de las pocas formas de aumentar las escasas retribuciones que en ocasiones recibían por parte de los Cabildos. Segorbe no va a ser una excepción a esta práctica, lo cual va a dar lugar a frecuentes conflictos entre el Cabildo y los músicos de la capilla catedralicia, como el que acontece en agosto de 1742, fecha en que se decide multar de manera irrevocable con treinta reales a tres miembros de la capilla por no haber asistido a la festividad de San Ignacio de Loyola, tal como lo había ordenado el Cabildo. ${ }^{36}$

Otra cuestión relacionada con la anterior y también de índole económica se refiere a las actuaciones de la propia capilla musical en actos fuera de la catedral. Se desata la polémica cuando se deja de contratar a la capilla en las fiestas de los barrios de Segorbe con el pretexto de la

31. ACS, 8-2-1741.

32. Véase Apéndice I, Doc. 12.

33. Véase Apéndice I, Doc. 13.

34. ACS, 9-12-1741.

35. Véase Apéndice I, Doc. 14.

36. Véase Apéndice I, Doc. 15. 
falta de recursos económicos. Como este pretexto no convence al Cabildo, se toman una serie de medidas en el sentido de no decir misa alguna durante dichas fiestas, salvo que se contrate a la capilla de la catedral. ${ }^{37}$

Ya hemos aludido con anterioridad al caso de Lorenzo Heredia en 1741 y a la costumbre de solicitar la anulación o la minoración de una multa. Se trata de una costumbre habitual en la vida catedralicia del siglo XVIII español, y esto mismo vuelve a ocurrir con el mencionado caso de los tres miembros de la capilla que habían dejado de asistir a la festividad de San Ignacio. A pesar del carácter «irremisible» de la multa, el Cabildo de Segorbe acaba por condonarla. ${ }^{38}$

Durante el magisterio de Conejos Ortells se hace mención de nuevo del que será su sucesor, José Gil, quien solicita permiso al Cabildo para ampliar y perfeccionar sus estudios en Valencia, donde permanecerá dos años (1743-1744). ${ }^{39}$

Otro motivo de loable preocupación para el Cabildo es la conservación del patrimonio musical de la Catedral así como la brillantez de la música eclesiástica ejecutada: con el fin de lograr este último objetivo se exige a Conejos Ortells que no se interpreten las mismas obras a menudo sino que impere la variedad en la elección del repertorio, incluso con obras musicales diferentes a las existentes en el archivo musical de la catedral de Segorbe. Por último se insiste en el control y aprobación de los textos de los villancicos antes de que éstos sean compuestos por Conejos Ortells. ${ }^{40}$

A lo largo de este artículo hemos podido observar cómo los miembros del Cabildo multan o advierten a los músicos cuando éstos dejan de cumplir con las obligaciones inherentes al cargo. Así ocurre en febrero de 1745: el Cabildo llama la atención a los músicos y les ordena que asistan a los maitines para responder a los chantres. ${ }^{41}$

A mediados de 1745 se replantea la problemática derivada de la actuación de los músicos de la capilla en funciones ajenas a la catedral, y a la cual nos habíamos referido con anterioridad. En esta ocasión el Cabildo expresa su preocupación por la pérdida de «voz y salud» que ocasionan estas actuaciones, que perjudican ante todo la brillantez de la música interpretada en la catedral. $^{42}$

En ese mismo mes de mayo de 1745 se plantea la adquisición de dos trompas, lo cual indica un cambio estilístico notable, ${ }^{43}$ ya que las trompas sustituyen a los clarines, instrumentos representativos de la música barroca española, y se hacen prácticamente imprescindibles en buena parte de las catedrales españolas. Las mencionadas trompas serán ejecutadas por dos músicos de la propia ciudad de Segorbe:

37. Véase Apéndice I, Doc. 16.

38. Véase Apéndice I, Doc. 17.

39. Véase Apéndice I, Doc. 18.

40. Véase Apéndice I, Doc. 19.

41. Véase Apéndice I, Doc. 20.

42. Véase Apéndice I, Doc. 21.

43. En opinión de Rummenhöller, la introducción de las trompas ha de ser entendida en el marco de la decadencia de la música barroca basada en el bajo continuo. La función del continuo será asumida por las trompas, función que en definitiva viene a constituir una especie de «pedal» de la orquesta. Véase RuMmEnhöller, P.: Die musikalische Vorklassik, dtv/Bärenreiter, Kassel 1983, pág. 92. 
«Asimismo: por cuanto por el ilustre Cabildo se tuvo presente que buscándose dos trompas, se adiestrarían algunos de los músicos de esta ciudad. Se tomaron dos que importó su coste con las boquillas y cajón para la limpieza y conservación de dichas trompas: 20 L[ibras], lo que se sacó de prepositura». ${ }^{44}$

Debido a la avanzada edad de Conejos Ortells y a su incapacidad para dirigir la capilla de música, el Cabildo nombra un sustituto el 9 de agosto de 1745, función que recae en José Gil, antiguo acólito de coro de la catedral de Segorbe y que había permanecido en Valencia para perfeccionar sus estudios musicales. Este será el primer paso de Gil para regentar de manera definitiva la dirección de la capilla. Entre las funciones que el Cabildo otorga a Gil se encuentra asimismo la enseñanza de los mozos de coro — «Infantes»—, obligación que llevaba aparejada el magisterio de capilla. ${ }^{45}$

José Conejos Ortells falleció el 3 de diciembre de 1745, después de 29 años de fructífero magisterio, tal como recoge la siguiente noticia capitular:

«En 4 de diciembre de 1745, se dio eclesiástica sepultura a mosén José Conejos, Maestro de Capilla de esta Santa Iglesia Catedral; hizo testamento ante Manuel Soriano, escribano de la villa de Altura, a 16 del mes de junio del mismo año; y en él dispuso sus obras pías en la forma siguiente: primeramente quiso se le hiciere aquel entierro que se acostumbra hacer en esta Santa Iglesia a sus residentes, y concluidos todos los actos, le sea librada eclesiástica sepultura en la Capilla de todos Santos, donde colocó a sus expensas a San José y San Blas, y que a más de que sus bienes se tome lo que sea necesario para pagar su funeral: que se saque igualmente para pagar doscientas misas, con limosna de cuatro sueldos para que se celebren 100 en la Catedral por sus residentes, y las otras 100 , sacadas 30 misas, 10 para cada uno de los conventos de San Pablo, San Blas y Santa Ana, las demás a disposición de mis albaceas...». ${ }^{46}$

Sin embargo, su testamento causará diez años después de su muerte una fuerte controversia. En su testamento, Conejos expresaba su deseo de «fundar y hacer celebrar cinco misas perpetuas cantadas [en] modo recitativo en la capilla ahora de san José y san Blas del claustro de esta Santa Iglesia», deseo que no es autorizado por el Cabildo pues la celebración de las citadas misas y la almoneda de los bienes de Conejos es perjudicial para los intereses económicos del Cabildo. ${ }^{47}$

44. ACS, 17-5-1745.

45. Véase Apéndice I, Doc. 22. En otras centros musicales se obliga al maestro de capilla a vivir con los mozos de coro, infantes o cantorcicos o seises, denominaciones que dependen de la catedral respectiva. Esto es lo que ocurre por ejemplo en la Real Capilla: el maestro de capilla vive en el propio Colegio de Niños Cantorcicos, enseña a los niños con el ejemplo de su vida y el trabajo de su misterio para que salgan diestros cantores. El Maestro se hará cargo del gobierno de la Casa y el Colegio, cobros y pagos, y abonará con puntualidad los honorarios al barbero, zapatero, sastre y lavandera y demás oficiales que sirven dicha casa... «y los castigará el Rector si sabe que han estado en algunos lugares indecentes, como en las Comedias, y en otras partes no lícitas, mayormente si fuesen sin licencia». Véase SUBIRÁ, J.: «La música en la Real Capilla madrileña y en el Colegio de Niños Cantorcicos», Anuario Musical, vol. XIX, 1959, pág. 219ss.

46. ACS, 4-12-1745. Citado en PERPIÑan, op. cit., nº 14, 1897, pág. 221.

47. Véase Apéndice I, Doc. 23. 
Al día siguiente se plantea nuevamente el problema, reafirmándose el Cabildo en la no aceptación de las condiciones impuestas en su testamento por Conejos, si bien se ofrece «una misa cacnonical solemne» en vez de las cinco misas perpetuas en modo recitativo. ${ }^{48}$

Las obras conservadas de Conejos son las siguientes: villancicos.

- Catedral de Segorbe: 1 misa, 3 motetes, 11 salmos, 1 magnificat, 18 tonos, 6 dúos y 13

- Catedral de Valencia: 3 Salmos, 1 Magnificat y 1 Lamentación.

- Colegio del Patriarca de Valencia: 13 misas, 3 Lamentaciones, 10 Motetes, 56 Salmos, 5 Versos, 6 Magnificat, 2 Cánticos, 3 Villancicos y 1 Rosario.

\section{José Gil Pérez}

Nació en Segorbe el 19 de junio de 1715 e ingresó en la catedral, como infantillo, en mayo de 1726. Primero fue infantillo (1726-1732) y posteriormente mozo de coro (1732-1742) de la catedral de Segorbe, donde estudió bajo la dirección del entonces maestro de capilla, José Conejos Ortells. Entre 1743 y 1744 residió en Valencia, perfeccionándose en la composición musical, contando para ello con la ayuda del cabildo segorbicense, tal como veremos después.

Ya vimos al hablar de Conejos como fue nombrado su ayudante y posteriormente regente de la capilla el 9 de agosto de 1745. Analicemos las actas capitulares que se han conservado sobre el magisterio de Gil Pérez: habíamos visto como en febrero de 1745 se reprendía a los músicos para que asistieran a los maitines y cantaran alternativamente con los chantres. Justo un año después vuelve a abordarse el problema del canto alternativo de los versículos entre los chantres y los miembros de la capilla durante la celebración de los maitines, dándose prioridad en el canto de salmos y antífonas a los chantres:

«Se deliberó que para la mayor observancia en el modo que se debe cantar en el coro se pusiera un papel, que es del tenor siguiente: se previene que en los días que hubiere maitines sólo los chantres canten el invitatorio, y éste alternativamente se cante por los músicos, que para este fin bajan al facistol, y asimismo que por cuanto privativamente pertenece a los chantres el entonar el primer verso de los salmos y cualesquiera antífonas, los dichos lo deban así practicar solamente, a excepción de los tan dados por los dichos chantres». ${ }^{49}$

Valencia seguía constituyendo para el Cabildo la ciudad idónea para que los cantores y ministriles de la capilla musical de la catedral de Segorbe perfeccionasen su formación musical. Así ocurrió con José Gil durante la época de Conejos y es el caso que nos ocupa en febrero de 1746, ya durante el ejercicio de Gil: se trata de Atanasio Andréu, a quien se otorga un año adicional para que amplíe su formación musical, sin especificar en este caso a qué instrumentos se refiere la causa de la estancia en Valencia, si bien en otro documento se habla de la chirimía:

48. Ibidem.

49. Véase Apéndice I, Doc. 24. 
«Asimismo: habiéndose hecho cargo los dichos señores que para la mayor perfección y adelantamiento en los instrumentos que ha aprendido Atanasio Andréu, necesitaba de estar algo más de tiempo en Valencia, se deliberó bajara a dicha ciudad para dicho fin, y que para ello se le daba de tiempo un año, y se contara desde Navidad del año 1745 hasta Navidad del año 1746». ${ }^{50}$

En noviembre de ese mismo año, el Cabildo exige a Andréu que se reincorpore a la capilla de Segorbe con el fin de que participe en las celebraciones de la Inmaculada y asuma definitivamente la capellanía de chirimía. ${ }^{51}$

Las relaciones con los pueblos limítrofes a Segorbe no parecen haber estado exentas de tensiones. Así, durante la celebración de la Semana Santa de 1746, el Cabildo prohíbe taxativamente a los miembros de la capilla que asistan como tal agrupación o en calidad individual a la procesión del pueblo vecino de Altura. ${ }^{52}$ En la misma reunión capitular del dos de abril de 1746 se pide cuentas al capellán encargado del uso del campanario. ${ }^{53}$

Con motivo de la exaltación al trono del rey Fernando VI, en agosto de 1746 se organizan una serie de actos religiosos, en los que la capilla de Segorbe dirigida por José Gil desempeña un papel relevante al celebrarse «una Misa Canonical post Nonam con música por dicha intención» así como «cantarse la letanía mayor en el Presbiterio, con las preces del caso que se resolverán con consulta del Maestro de Ceremonias, acompañando la música, concluyéndose así la función». ${ }^{54}$ Días después se vuelve a tratar el mismo tema e, imitando el ejemplo de Valencia, se canta una misa de acción de gracias y se organiza una procesión. ${ }^{55}$

Tras once años fue nombrado sin oposición Maestro de Capilla titular el 24 de mayo de 1754, siguiendo la opinión de quienes le conocieron en Valencia y de algunos de los componentes de la capilla musical de Segorbe:

«Teniendo presente que el Maestro don José Gil regía hacía ya 10 años la Capilla por haberle nombrado el Cabildo sustituto del difunto Maestro mosén José Conejos y que viviendo aun éste, haber hecho concepto de su habilidad... teniendo muy en memoria que ha continuado hasta el día de hoy desempeñando la obligación y muy presente los buenos informes que sobre su habilidad se han tenido de Valencia, como asimismo que en todo tiempo ha dado testimonio suficientísimo, teniendo por otra parte el Ilustrísimo Cabildo deseos de acomodarle, supuesto que desde niño servía a esta Iglesia, por haber sido en ella infantillo y después mozo de coro, sin haberla dejado más que dos años, que los empleó en Valencia instruyéndose en la composición antigua y adelantándose en la moderna: nemine discrepante acordó el Cabildo que sin embargo de todas las razones que preceden, para mayor formalidad, que mosén Lorenzo Juan, contralto, y mosén Joaquín Gómez, tenordomero, que entraran en Cabildo a fin de que certificaran si en el tiempo que fue regente el

\author{
50. Ibidem. \\ 51. Ibidem. \\ 52. Véase Apéndice I, Doc. 25. \\ 53. Véase Apéndice I, Doc. 26 \\ 54. Véase Apéndice I, Doc. 27. \\ 55. Ibidem
}


citado Gil, habían formado juicio de que era hábil en la composición y benemérito para ocupar en propiedad la plaza vacante; y habiendo manifestado éstos diferentes razones que aseguraron al Cabildo los buenos informes de Valencia... nombrándole Maestro de Capilla, admitiéndole a las distribuciones, etc y con 30 libras de salarios; se le concedieron contenidas en la escritura de erección de la Capellanía, que recibió el Notario Don José Torrens Español... y en atención a que tiene voz de contralto, que cante el Evangelio». ${ }^{56}$

A pesar del tiempo transcurrido desde la muerte del antecesor de José Gil en el cargo de maestro de capilla de Segorbe, José Conejos Ortells, es ahora cuando se dilucida el beneficio que le corresponde a José Gil. Se acuerda que disfrute el mismo beneficio que poseía Conejos, beneficio que sin embargo había estado obteniendo Miguel Martín. ${ }^{57}$ A pesar de dicho acuerdo capitular, fechado el 16 de agosto de 1754, el 23 del mismo mes y año, Miguel Martín protestó y fueron necesarias nuevas diligencias para averiguar quién de los dos, José Gil o Miguel Martín, tenía derecho preferente para disfrutar del beneficio del priorato. ${ }^{58}$

Las relaciones de Gil Pérez con el Cabildo no parece que fueran siempre cordiales, como lo demuestra el documento capitular en el que se reprocha al maestro de capilla los términos irrespetuosos con que se ha dirigido al presidente del Cabildo y se mantiene la multa impuesta a José Gil Pérez por haber faltado dos infantillos a unas Vísperas. Además el Cabildo le recuerda a Gil sus obligaciones para con la educación de los infantillos. ${ }^{59}$

José Gil ocupó el cargo de maestro de capilla hasta su muerte, que tuvo lugar el 21 de marzo de 1762. Según Perpiñán, «se le dio sepultura eclesiástica en el sepulcro de la hermandad, al día siguiente a su fallecimiento, don Juan Pinazo, regente de la parroquia del Salvador de la misma Catedral». ${ }^{60}$

Se conservan en la Catedral segorbina las obras siguientes: 6 misas de gloria, 1 misa de requiem, 21 lamentaciones, 8 motetes, 37 salmos, 1 completas, 1 verso, 7 magnificats, 1 antífona, 1 himno, 2 secuencias y 105 villancicos.

\section{Francisco Vives}

Francisco Vives accedió al cargo de maestro de capilla de la Catedral de Segorbe del 29 de mayo de 1762. Las oposiciones habían tenido lugar el 1 de mayo de 1762, tras la muerte del anterior maestro, José Gil Pérez, en marzo de aquel mismo año. Entre los que actuaron como examinadores de aquella oposición se encuentra Juan Acuña ${ }^{61}$ y Pedro Guillén, maestro de San Mar-

56. Citado en Perpiñan, op. cit., nº 15, 1897, pág. 236.

57. Véase Apéndice I, Doc. 28.

58. Véase Apéndice I, Doc. 29.

59. Véase Apéndice I, Doc. 30.

60. PERPIÑAN, op. cit., $\mathrm{n}^{\circ} 15,1897$, pág. 238.

61. Juan de Dios Aguilar Gómez afirma que Juan de Acuña era natural de Elche, desde donde se trasladó a Valencia, donde desempeñó el cargo de maestro de capilla en la Parroquia de San Martín y beneficiado de la de Santa Catalina Mártir, desde donde pasó al magisterio de la parroquia de los Santos Juanes. Además de música religiosa, que se conserva en las catedrales de Segorbe y Orihuela, escribió dos zarzuelas trágico-cómicas y varios oratorios. Véase AGUILAR GómEZ, J. de D.: La música en la provincia de Alicante, Instituto de Estudios Alicantinos, Alicante 1983, pág. 367s. 
tín de Valencia. Uno de los opositores que acudieron a dichas oposiciones fue Francisco Garzón, que obtuvo además dos votos.

Encargado del magisterio Vives, el Cabildo ordenó se cantara el canto de atril que ya se ejecutaban; y por fin que no se repitieran las mismas obras. ${ }^{62}$ El 2 de junio de 1762 el deán entregó al nuevo maestro los inventarios, en los que había muchas misas que no se cantaban por negligencia de los músicos, así como un libro de música de atril escrito por Eliseo Boronat y otro impreso «estos últimos años» (refiriéndose al libro de misas de José de Torres). Se solicita a Vives que exponga los referidos libros en el facistol para que se canten en las respectivas solemnidades de la Iglesia y teniendo en cuenta su «habilidad y circunstancia de perfecto organista, en atención a ser esta una de las condiciones puestas en los edictos», se le ordena que taña el órgano durante varios días y solemnidades, y que pueda hacerlo «sin notable falta de la dirección de la Capilla». ${ }^{63}$

Durante su magisterio, no faltan las llamadas de atención del Cabildo a los miembros de la capilla por sus continuas faltas del coro:

"Que se advierta a los músicos que el día que falten al coro habiendo música se les multara... Se concede licencia a mosén Atanasio de 15 días dejando otro en su lugar. Y al Maestro de Capilla para hacer los ejercicios en sancti spiritus según se expresa en la deliberación el 10 de agosto del $1768 »{ }^{64}$

En Segorbe permaneció hasta el 24 de noviembre de 1771, año en que ingresó en el Monasterio de San Miguel de Reyes. En 1793, Francisco Vives desempeñaba el puesto de organista en dicho monasterio cuando el Cabildo de Segorbe le escribió, pidiéndole informes sobre la suficiencia de don José Gil, maestro de Teruel, para agraciarle con el magisterio de aquella Catedral, vacante por promoción de José Morata en Játiva. Francisco Vives falleció a los 57 años el 5 de noviembre de 1799.

Se han conservado de Vives las siguientes obras en la catedral de Segorbe:1 misa, 3 salmos, 1 secuencia, 1 verso, 1 cántico, 1 dúo y 26 villancicos.

\section{Vicente Olmos}

Nació en Catarroja (Valencia) en torno a 1745. Se inició como infantillo de la catedral de Valencia «en 12 de diciembre de $1754 » .{ }^{65}$ Fue nombrado «mosso de capella» el 22 de junio de $1762 .{ }^{66}$ Fue acólito de la misma catedral, de donde, por oposición, pasó a ocupar el cargo de maestro de capilla de la catedral de Segorbe el 28 de febrero de 1772, celebrándose los ejercicios de oposición el 19 de febrero de aquel año. Según Perpiñán «poco o nada dicen las actas y otras

62. Citado en Perpiñan, op. cit., nº 17, 1897, pág. 268.

63. Ibidem.

64. ACS, 1-X-1769.

65. Perpiñan, op. cit., núm. 13, 1897, pág. 269

66. Actas capitulares de la Catedral de Valencia (ACV), vol. 1631. Citado en Climent, op. cit., pág. 184. 
fuentes sobre él». ${ }^{67}$ El 16 de octubre de 1779 se retiró al Monasterio de Jerónimos de la Murta (Alcira-Valencia) y en una carta fechada el 8 de noviembre de 1780 comunicaba al Cabildo que había hecho profesión solemne en el día primero de dicho mes y año, por lo que quedó vacante la capellanía de Maestro de Capilla, si bien nueve años después (20 de enero de 1789) remitió al archivo segorbino unos salmos de vísperas. En el citado monasterio seguramente falleció. Las obras de Olmos existentes en el archivo de la catedral de Valencia son posteriores a su ingreso en la Murta pues llevan el nombre adquirido en el convento: Fray Vicente de Nuestra Señora de los Desamparados Olmos.

Las obras musicales conservadas de Olmos son las que siguen:

- Catedral de Segorbe: 1 misa, 2 lamentaciones, 6 salmos, 1 completas, 1 magnificat y 35 villancicos.

- Catedral de Valencia: 3 Lamentaciones y 1 Salmo.

\section{José Gavaldá}

Gracias a la serie de artículos publicados por José Perpiñán en la revista «La música religiosa en España» conocemos la presencia de este autor, ya que buena parte de las actas capitulares del siglo XVIII se perdieron durante la Guerra civil española. Según las noticias proporcionadas por Perpiñán, el obispo Fray Alonso Cano, el 9 de Mayo de 1778, después de estudios y conferencias con el Cabildo Catedral, había otorgado un decreto de supresión y reducción de beneficios así como de creación de capellanías, asignando a cada uno sus correspondientes oficios, que son los siguientes con respecto a la música: cuatro sochantres, Maestro de Capilla, organista, ayudante de estos dos, dos domeros, dos contraltos (uno de $1^{\circ}$ y otro de $2^{\circ}$ coro), dos tenores (uno de $1^{\circ}$ y otro de $2^{\circ}$ coro), dos bajones, un oboe o chirimía, un violón, evangelisterocontralto, epistolero-tenor, escritor de libros de coro y dos salmistas, además de seis infantillos.

Gavaldá había probado su mérito y suficiencia en la brillante oposición que en 1772 ganó Olmos, y el Cabildo le confirió una Capellanía con los cargos de suplente del Maestro de Capilla y del organista, además de primer tenor y director de la escuela de música. Según Perpiñán «Tal vez su modestia no le permitió opositar a la plaza de $1^{\circ}$ maestro en 1779 , en cuya oposiciones actuó con el primer organista Casaña como censor, en vista de lo cual y en recompensa bien merecida se le agració con la capellanía de Ayudante del Maestro de Capilla y $2^{\circ}$ organista, una de las 33 del Obispo Cano». ${ }^{68}$

Murió el 11 de abril de 1804:

«En 12 de abril de 1804, yo, don Juan Mínguez, vicario, dí sepultura en el vaso de la Venerable Hermandad de Beneficiados y Capellanes a mosén José Gavaldá, Presbítero, capellán residente en esta Catedral; recibió los sacramentos, e hizo testamento...». ${ }^{69}$

67. Citado en Perpiñan, op. cit., n 17, 1897, pág. 269.

68. Ibidem, pág. 270.

69. Ibidem, pág. 270. 


\section{Joaquín López González}

Según José Perpiñán en su artículo publicado en la revista La música religiosa en Espa$\tilde{n} a,{ }^{70}$ era natural de Bolliga (Cuenca) y sucedió a Vicente Olmos en el magisterio de capilla de Segorbe el 26 de enero de 1781, interviniendo como examinadores el organista José Casaña y José Gavaldá. A las obligaciones inherentes al cargo de maestros anteriores, el Cabildo añadió la de enseñar canto y composición a los que habiendo sido infantillos lo solicitasen.

Recibió la sagrada orden del Presbiterado en marzo de 1783 y entre los destacados alumnos que se formaron bajo la tutela de este maestro se cuenta a José Morata, figura de primera magnitud en Segorbe. Renunció al magisterio de Segorbe por haber obtenido media ración afecta al Magisterio de la Catedral de Orihuela, ${ }^{71}$ según certificado que remitió al Cabildo de Segorbe el cinco de noviembre de 1785. Falleció siendo maestro de Orihuela en agosto de 1815, sucediéndole en el cargo José Aleixandre.

Se conservan las siguientes obras de López:

- Catedral de Segorbe: 2 misas, 20 salmos, 1 lamentación, 7 cánticos, 1 himno y 14 villancicos.

- Catedral de Valencia: 1 Misa, 2 Salmos y 7 Villancicos.

- Catedral de Orihuela: 6 misas, 17 lamentaciones, 20 motetes, 32 salmos, 1 invitatorio, 3 versos, 1 letanía, 3 cánticos, 5 antífonas, 2 himnos, 1 secuencia, 1 dúo y 61 villancicos.

\section{José Morata García}

Este autor permaneció como maestro de capilla de la catedral de Segorbe en dos períodos diferentes: 1786-1792 y 1815-1829. José Morata García nació el 27 de enero de 1769 en Geldo, una pequeña aldea de Segorbe, según consta en la siguiente partida de bautismo:

«En 27 de enero de 1769 a las tres de la mañana en este pueblo de Geldo, Juan José Joaquín Morata García, hijo legítimo de José y Josefa. Abuelos paternos, Jerónimo Morata y María García; maternos Juan García e Isabel Ros. Padrinos, Juan Esteban y Rosa García; bautizado por el Doctor Silvestre Collado». ${ }^{72}$

Según Perpiñán, gracias a la petición de sus padres, consiguió a los nueve años (15 de julio de 1778), mediante oposición previa, una plaza de infantillo en la Catedral de Segorbe. Bajo la dirección del maestro Amós y después del maestro López, hizo notabilísimos avances, no sólo en el solfeo y canto, sino que a los 15 años se convirtió en un maestro consumado del contrapunto, armonía y composición, como lo prueban las obras que escribió en esa época a 9 y 8 partes - por ejemplo, el Domina probesti me a 8 voces. $^{73}$

70. Perpiñan, op. cit., núm. 18, 1897, pág. 283.

71. Véase Apéndice II, Doc. 1.

72. Libros Parroquiales de Geldo. Citado en Perpiñan, op. cit., nº 18, 1897, pág. 284.

73. Ibidem, pág. $284 \mathrm{~s}$. 
Debió ser un niño prodigio ya que a la temprana edad de 17 años, el 28 de febrero de 1786, se le nombró maestro de capilla de Segorbe por unanimidad: vacante el magisterio de Segorbe por el traslado de López a Orihuela, hace oposiciones. Los ejercicios de la oposición trascurrieron de la siguiente forma, según nos ha trasmitido Perpiñán:

«Terminó el plazo del edicto en 15 de febrero; eran tres los opositores, la comisión capitular se componía de los canónigos señores Zalón y Soriano; examinadores, don José Casaña y don José Gavaldá. Empezaron los ejercicios el día 20, quedando abierto el concurso durante las oposiciones. El opositor Francisco Jiménez pidió que los opositores estuvieran separados e incomunicados las 24 horas del ejercicio de composición. El día 27 la comisión capitular hizo presente como Mariano Vicent y Agramuntell, y José Morata habían cumplido exactamente todos los ejercicios, pero que José Francisco Jiménez solamente con los del primer día, por haberse indispuesto, como habían certificado los médicos. La elección tuvo lugar el día 28 siendo nombrado nemine discrepante José Morata; aceptada la capellanía mediante juramento, se recibió escritura pública ante el notario Bonifacio Polo Benet. Dieron la gratificación a los censores diez libras y otras diez a los músicos que tomaron parte en dichos actos». ${ }^{74}$

La única documentación existente hoy día en la catedral que hemos podido localizar se refiere a la forma de aquella oposición: «Día 18 de enero [1786] se acordó que los opositores al magisterio de Capilla estén cerrados con separación las 24 horas de ejercicio de composición». ${ }^{75}$

Al poco tiempo de tomar posesión, el Cabildo recompensa al organista, José Casaña, «en razón de sus muchas y buenas circunstancias». Ello tiene lugar el 5 de noviembre de 1786:

«En 20 se aumentaron al organista mosén Casaña Cuarenta libras sobre su sueldo, 20 de fondo de sueldo, diez de la administración de prepositura, y diez de fábrica, pero sólo por vía de gratificación mientras dicho Casaña esté en el órgano y no por aumento de sueldos, en razón de sus muchas y buenas circunstancias». ${ }^{76}$

Esta gratificación se ve aumentada diez días después: «Día 15 de idem. La fábrica aumenta diez libras más de sueldo o gratificación del organista Casaña». ${ }^{77}$

En el acta de posesión de José Morata se dice lo siguiente: «Se trató de los medios de adelantar y perfeccionar más el nuevo Maestro de Capilla en el buen gusto de la composición en atención a su corta edad y talento sobresaliente que manifiesta por la música». ${ }^{78}$ A tal fin se resolvió enviarle a Valencia para que ampliara estudios con el entonces maestro de la catedral metropolitana, Francisco Morera:

«... que Morata se coloque en Valencia bajo la dirección del Maestro de Capilla de aquella Metropolitana, Francisco Morera, dándole 25 libras de las 50 que tenía de salario a José

\footnotetext{
74. Ibidem, pág. 285.

75. ACS, 18-I-1786.

76. ACS, 5-XI-1786.

77. ACS, 15-XI-1786.

78. Ibidem.
} 
Gavaldá por suplirle, y las 25 restantes juntamente con las distribuciones manuales para que pudiera costearse los alimentos en Valencia. Además, el señor Obispo, don Lorenzo Gómez de Haedo, por un efecto de su notoria generosidad, le proveyó abundantemente de ropa y se ofreció a costearle todo lo demás que faltare para una decente manutención en Valencia». ${ }^{79}$

Bajo la dirección del maestro Morera perfeccionó en Valencia sus conocimientos musicales. El 4 de Noviembre de 1786 escribía al Cabildo «que deseaba volver a Segorbe con el fin de enseñar a los infantillos las nuevas obras compuestas en Valencia». ${ }^{80}$ En Segorbe permaneció hasta el 20 de diciembre de 1792, fecha en que ocupó la maestría de la colegiata de Játiva, siendo desempeñado el magisterio por José Gil, Francisco Santafé y Francisco Andreví.

Durante este primer período segorbino (1786-1792), Morata enseñó música a los infantes y demás miembros de la Capilla, cuestión por lo que fue elogiado a menudo por el Cabildo. No son conocidas las razones por las que se trasladó a Játiva, catedral y centro musical de menor importancia que Segorbe pero según Perpiñán se debe tener en consideración que por esta época se reedificaba la Catedral por el anteriormente citado obispo Gómez de Haedo, cuya obra hubo de ocasionar estrecheces en el clero y sus dotaciones; además surgieron cuestiones que no agradaron a Morata: de las actas del 24 de septiembre de 1787 se deduce que por faltar a una misa de la Iglesia de San Pedro, cantada por el capitular señor Abad -éste se apoyaba en un acuerdo que decía: «siempre que algún canónigo cantara misa de la Iglesia de la ciudad, fuesen allí los músicos necesarios con su Maestro, el cual llevaría los correspondientes papeles de música»-, fue llamado al orden por el Cabildo, además de recibir la correspondiente multa, por lo que pudo concebir la idea de abandonar Segorbe. Así ocurrió cuando el 20 de noviembre de 1792 fue nombrado mediante oposición Maestro de Játiva. Largos años pasó Morata en Játiva, habiendo intentado, en 1814 , pasar a Cartagena. ${ }^{81}$

Las circunstancias de su regreso a Segorbe sucedieron de la siguiente manera: vacante el magisterio de Segorbe por el traslado de Francisco Andreví a la parroquia de Santa María del Mar en Barcelona, y pretendido por Honorato Verdeguer, Nicolás Ledesma - maestro y organista de Tafall, propuesto entonces en primer lugar para el magisterio vacante en la metropolitana de Nuestra Señora del Pilar de Zaragoza-, y el Maestro de Capilla de Rubielos, el Cabildo pasó a examinar las condiciones musicales de los opositores: resultó excluido Verdeguer, a pesar de los buenos informes a su favor de Andreví, ya que estaba casado. Después, por la estrechez de las rentas de su capellanía, Ledesma se retiró, haciendo lo mismo el maestro de Rubielos, quedando desierto el concurso, aun a pesar de haber remitido su composición de prueba el citado Verdeguer. Sin maestro y aproximándose las festividades de Semana Santa, el Cabildo de Segorbe decidió llamar a Morata con ventajosas condiciones, y se le otorgó por segunda vez el magisterio el 5 de mayo de $1815 .^{82} \mathrm{El}$ acta de su segunda posesión en Segorbe dice así:

79. Ibidem.

80. PERPINAN, op. cit., nº 19, 1897, pág. 294.

81. Ibidem.

82. Ibidem, pág. 295. 
«El señor Presidente manifestó que a consecuencia de lo resuelto por el Cabildo, había escrito a don José Morata, Maestro de la Capilla de la Catedral de Murcia, indicándole el aprecio que hacía este cuerpo de sus conocimientos nada comunes en la composición, unidos con el más delicado gusto, y su disposición y aptitud para la enseñanza de los infantillos y demás músicos, ofreciéndole todo el aumento de la dotación compatible con el estado de las rentas de la Iglesia». ${ }^{83}$

Existe una duda: Morata es llamado «Maestro de Cartagena», así como «Maestro de Murcia» y «Maestro de Játiva». Con seguridad lo fue de Játiva y debió ser un error de los copistas denominarlo maestro de las otras catedrales, como lo prueba el edicto de Játiva del 10 de septiembre de 1817:

«Nos el Deán y Cabildo de Játiva hacemos saber que se halla vacante en esta insigne Iglesia colegial, la plaza de Maestro de Capilla por traslación de José Morata a la Catedral de Segorbe; cuya plaza, que es cóngrua, tiene la obligación de regir la capilla... componer los villancicos de Navidad y Miserere en alguna Semana Santa... y además, la enseñanza diaria de los infantillos... y para ello tiene la renta de un beneficiado (50 libras anuales) y 60 que le paga la Ilustre Ciudad, con los emolumentos que han gozado sus antecesores y de 2 meses de solaz». ${ }^{84}$

En 1819 intentó Morata salir por segunda vez de Segorbe y opositó al cargo de maestro de la catedral de Valencia. Opositaron con él, Antonio Ibáñez, maestro del Pilar de Zaragoza, y Francisco Andreví, de Santa María del Mar de Barcelona, que fue el elegido. Diez años más tarde, el jueves, 16 de junio de 1829, fue elegido maestro del Patriarca. Los ejercicios del 30 de mayo de 1829 fueron censurados por los hermanos Joaquín y José Gil, tenor y maestro de capilla, respectivamente, de la catedral de Segorbe. Del Libro de Nominación de Capellanes del Colegio del Corpus Christi o Patriarca se afirma lo siguiente:

«En 14 de septiembre de 1824 se fijaron edictos para proveer la plaza de Maestro de Capilla. No se presentó ningún opositor... Y volvieron a fijarse en 24 de abril de 1829 . En 30 de mayo se presentó a firmar don José Morata, presbítero, Maestro de Capilla de Segorbe, natural de Geldo, edad 55 años [en realidad contaba con 60 años] y para la oposición se le mandó componer el Salmo De profundis a 12 voces, y el Himno de N. B. F. y señor, que trabajó sobre el canto llano; se nombraron por censores a don Joaquín y don José Gil, presbíteros; y habiendo éstos examinado las obras que presentó, las aprobaron y dieron censura de que el himno estaba hecho con mucha maestría... El jueves 16 de junio, día del corpus, fue elegido con todos los votos Maestro de Capilla con los emolumentos y distribuciones de Capellán primero y salario de 150 libras, pero sin casa, con las preeminencias que señalan las constituciones, y obligaciones que se marcan en las mismas, debiendo enseñar también a los mozos de coro». ${ }^{85}$

83. PERPIÑAN, op. cit., nº 20, 1897, pág. 319.

84. Ibidem.

85. PERPIÑAN, op. cit., nº 22,1897 , pág. 349. 
En una misa compuesta por Juan Bautista Plasencia, discípulo de Morata y escrita para las exequias de éste, se consigna su fallecimiento, ocurrido el 4 de febrero de $1840 .^{86}$

De José Morata se conservan las obras que a continuación se citan:

- Catedral de Segorbe: 5 misas de gloria, 1 misa de requiem, 36 salmos, 2 completas, 3 versos, 1 lamentación, 1 letanía, 1 secuencia del corpus, 9 magnificats, 3 cánticos, 3 antífonas, 2 himnos, 1 cantada y 46 villancicos.

- Colegio del Patriarca de Valencia: 5 Misas, 16 Salmos, 2 Versos, 4 Motetes, 2 Himnos, 1 Secuencia, 3 Magnificat y 1 Villancico.

- Catedral de Valencia: 1 Misa, 1 Lamentación, 1 Antífona mariana y 2 Villancicos.

- Catedral de Orihuela: 1 Misa, 2 Salmos, 1 Responsorio, 1 Magnificat y 1 Villancico.

\section{José Gil}

Resumimos los datos que sobre este maestro nos proporciona José Perpiñán. ${ }^{87}$ Mozo de coro desde el tres de enero de 1766 y antes, probablemente, infantillo de la Catedral de Segorbe, localizamos a José Gil con una plaza de músico en la Iglesia parroquial de Castellón en octubre de 1778, recibiendo posteriormente en Tortosa la tonsura clerical.

Posteriormente, en junio de 1790 , oposita a la colegiata de Rubielos, y posteriormente a la catedral de Teruel, cuya capilla dirige hasta su venida a Segorbe.

Sin oposición, «con el fin de evitar gastos por los muchos que ha tenido la Iglesia en la reedificación de su templo», y sólo mediante memorial e informes de los organistas de Segorbe, José Casaña, y San Miguel de los Reyes, Francisco Vives, es elegido para el magisterio, vacante por el traslado de Morata a Játiva el 20 de septiembre de 1793, con la obligación, además de las propias del Maestro de Capilla, de tañer el órgano y violón así como cantar de tenor siempre que fuera necesario. José Gil no había obtenido el cargo como beneficio colativo, por lo que solicita luego del Cabildo, que en atención a que estaba tonsurado, se le diera colación y posesión canóniga, lo que hizo el Cabildo, ordenándose y celebrando su primera misa en diciembre de 1794.

En 1797 actúa como examinador en las oposiciones al Magisterio de Rubielos. Se le aumenta su salario de Segorbe en 20 libras debido al el mucho trabajo con los infantillos y la composición de obras.

Renuncia al magisterio por haber obtenido el 13 de marzo de 1802 un beneficio congruo colativo con invocación del Santísimo Nombre de Jesús en la Parroquia del Salvador de Valencia, renuncia que no se le admitió hasta febrero de 1803 en atención a haber mandado los documentos referentes en papel simple.

Su hermano Joaquín obtuvo el 24 de julio de 1786 una de las capellanías de tenor erigidas por el decreto del Obispo Fray Alonso Cano, a la que renunció por haber pasado por oposición a otra de domero en la Metropolitana de Valencia a principios de 1791.

86. Ibidem, pág. 350 .

87. PERPIÑAN, op. cit., n 23, 1897, pág. 363. 
De sus obras conservadas, es necesario destacar que en el catálogo de José Climent no se distingue entre las obras de José Gil Pérez y el autor del mismo nombre que nos ocupa, agrupando las obras de ambos maestros como si fueran todas del primero, si bien José Perpiñán dedica artículos diferentes e indica que se conservaban 30 obras de este maestro, entre ellas el responso Libera me, a 8 voces y orquesta, compuesto para la exequias del Papa Pío VI. ${ }^{88}$

\section{APÉNDICE I}

\section{Documentación}

(Actas Capitulares de la Catedral de Segorbe)

Documento 1: Nombramiento de Mateo Peñalba como maestro de capilla de Segorbe (Acta del 20 febrero de 1691)

«Atendido y considerado que el Licenciado mosén Mateo Peñalba, ocho años ha que regenta la Capilla con la paz y sosiego... y con el adelantamiento de los infantillos y lo mucho que se aplica a la nueva música, así para las Navidades como para las festividades de los Jueves, Corpus Christi, festividades del rosario, ahorrándole el salario de Maestro de Capilla, y que estas diez libras las daba a mosén Antonio Martín por sustituirle la Chantría, y otros motivos justos y razonables como son: excusarse la Iglesia un personado y voz de cantor por suplir con su voz siempre que es menester; unánimes y conformes deliberaron se le adjudiquen 15 libras más y en los jueves un real además de lo que percibe por su personado y la media porción por regentar la Capilla. Otrosí: se le concede un mes de presencia además de la que han tenido los Maestros para la composición de Navidades, con objeto de que se aplique más y más a la nueva composición para las festividades de entre año, pudiendo valerse de dicha presencia, ya sea con continuación de días, ya sea con discontinuación, con calidad de que la música que componga haya de ser de esta Iglesia, entregándola ya con los originales, ya con copia de ellos... Y para mayor respeto y veneración que le deben tener todos los músicos, ha parecido bien a dichos señores nombrarle por Maestro de Capilla, dándole y confiriéndole todos los honores y preeminencias de que han gozado los demás Maestros de Capilla de esta Santa Iglesia».

Documento 2: Partida de defunción de Mateo Peñalba (Acta del 11 de junio de 1714)

«A once de Junio de 1714 se enterró [a] mosén Matheo Peñalba, Presbítero Chantre y Maestro que fue de Capilla de esta Santa Iglesia Catedral; hizo testamento de su propia mano, letra, y firma en 15 de Abril de 1676, nombrando albaceas a Matheo Peñalba, su padre, y a Luis Peñalba, su hermano, pero por haber premuerto los dichos, el Vicario General nombró albaceas a Vicente Ferrer de Gerónimo y a María Peñalba, su mujer, hermanos del difunto, a los que dio facultad para ejecutar la obra pía a su voluntad y éstos han tomado de los bienes y hacienda del difunto cien libras; diéronle sepultura dentro del cuerpo de la Iglesia, ante la Capilla del Carmen».

88. Ibidem. 
Documento 3: Plaza de contralto (Acta del 19 de agosto de 1731)

«Habiéndose declarado por sentencia de esta curia vacante la Capellanía de contralto de esta Santa Iglesia por razón de la larga ausencia del licenciado mosén Ambrosio Gómez, y habiendo hecho relación al Ilustre Cabildo el Licenciado mosén Baltasar Flor y mosén Antonio Díaz, músicos, de la habilidad y destreza del licenciado Lorenzo Juan, quien durante la ausencia de dicho Gómez ha suplido, como también de la utilidad que se espera tener esta Santa Iglesia con el referido Lorenzo Juan, por tanto deliberaron se le exija a favor de éste la Capellanía de contralto con el salario acostumbrado y demás emolumentos, con la obligación de obedecer lo que le mandare el Ilustre Cabildo y con la condición que haya de hacer residencia personal de su capellanía por manera que si faltare a la residencia voluntariamente o se ausentare por espacio de 6 meses por cualquier causa que fuere, aunque sea con motivo de no tener suficiente [ilegible] se entienda que vaque ipso facto dicha capellanía y que queda el Cabildo con la libre facultad de proveerla».

Documento 4: Petición de ayuda al Cabildo del contralto Lorenzo Juan (Acta del 15 de junio de 1733)

«Habiendo representado mosén Lorenzo Juan, presbítero contralto de esta Santa Iglesia su mucha pobreza y gastos que se le han seguido a ocasión de sus órdenes y considerando el Ilustre Cabildo de su mucha aplicación, trabajo y desempeño en el cumplimiento de su oficio, deliberaron se le dén $10 \mathrm{~L}$ más de salario, además del que se le paga, que serán en todo $23 \mathrm{~L}$ canónicas, cuyo asignamiento aumento hicieron dichos señores por hallarse en buen estado la administración de Prepositura. Asimismo deliberaron que en vista de lo que trabajaban en la Capilla los Infantes Joaquín Sancho y Francisco Selma se les dé a los dos una porción en las músicas de dentro y fuera de la Iglesia a voluntad de dicho Cabildo».

\section{Documento 5: Provisión de dos plazas de bajón (Acta del 1 de junio de 1734)}

«Asimismo deseando dichos señores proveer las dos plazas ordinarias de Bajón, vacantes por muerte de mosén Joseph y mosén Jorge Morante en Joseph Montero e Ignacio Fulla por los servicios que más de 10 años tienen hechos a esta Santa Iglesia para mejor proveer, nombraron por examinadores a mosén Baltasar Flor y a mosén Antonio Díaz, músicos para que, hecha por éstos relación y graduación de la ciencia y práctica de aquéllos, pueda el Ilustre Cabildo nombrar con todo acierto, para lo cual mandaron se hiciera convocatoria para el día 2; y por cuanto se previene en una constitución jurada de la Iglesia que estas plazas se provean por concurso, dichos señores pidieron relación del juramento al señor Deán Pombau por hallarse V. E., el cual atendidas las muchas razones que se representaron en Cabildo para hacer el nombramiento en los dichos sin la formalidad del concurso hizo la relación que se pidió».

\section{4)}

Documento 6: Admisión sin oposición previa de dos bajonistas (Acta del 2 de junio de

«Habiendo oido la relación jurada que hicieron en Cabildo mosén Baltasar Flor y mosén Antonio Díaz sobre la idoniedad y habilidad en lo respectivo a las capellanías de bajón de Joseph Montero e Ignacio Fulla, de las cuales se hallan vacantes por muertes de mosén Joseph y mosén Jorge Morante deliberaron el nombrarles por tales capellanes, admitiéndoles a todos los emolumentos pertenecientes a dichas capellanías, reservándose el Ilustre Cabildo el salario que tiene la de primer coro para aplicarlo en adelante al que lo mereciere de dos según su mayor aprovechamiento y les nombraron con la obligación de tañer el oboe u otro instrumento siempre y cuando se les fuere mandado por el señor Presidente. Y sin embargo de haber convenido en dichos nombramientos todos los arriba dichos Señores, lo protestó el señor canónigo Don Joseph Feliú, canónigo magistral, por las razones que se expresan en el papel de su protesta que se 
halla en el libro 4 de deliberaciones capitulares inserta y para la mayor firmeza de dichos nombramientos el señor Deán Pombau, que [ilegible] en Cabildo rebajó el juramento en cuanto fuere menester».

Documento 7: Admisión de un cantor e informe del estado del órgano (Acta del 15 de marzo de 1735)

«Asimismo habiendo experimentado que mosén Lorenzo Heredia, sochantre, puede servir en la capilla, deliberaron que además de los emolumentos que se le concedieron en libración de 8 de marzo del corriente año, se le dé porción entera en la Capilla en las músicas de dentro y fuera de la Iglesia... Asimismo deliberaron que el síndico capitular dé recado al síndico de la ciudad para que mande componer el reloj de la Catedral por hallarse todo descompuesto: y asimismo por razón de tener el mismo trabajo el órgano de esta Santa Iglesia por tener muchos de sus registros principales descompuestos sin poderse tañer, deliberaron que el síndico capitular represente a los señores de la junta de Fábrica la necesidad que padece para que lo manden componer».

Documento 8: Confirmación como sochantre del tenor Lorenzo Heredia (Acta del 17 de julio de 1736)

«Atendiendo y considerando que el licenciado Lorenzo Heredia, clérigo natural de la villa de Liria, con ausencia de mosén Vicente Selma, chantre de esta Santa Iglesia, está sirviendo el oficio de sochantre va para año y medio, cumpliendo en él exactamente y que su voz por ser de cuerpo sobre el discurso de dicho tiempo se ha conocido ser de mucho provecho para regir el coro con bastante destreza para el canto llano y cantar en la Capilla; atendiendo asimismo que el dicho sochantre en repetidos Cabildos ha suplicado que se le hiciera capellanía a fin de servir a esta Santa Iglesia y en ella poderse ordenar para acudir a sus obligaciones. Dichos señores, atendiendo a los sobredichos motivos, deliberaron nemine discrepante se le exija capellanía supernumeraria de tenor con la obligación y no sin ella de haber de servir por sí la sochantría. Por tanto que el dicho mosén Vicente Selma no se restituye a su empleo de chantre o este oficio no se provee en propiedad por el Ilustre Cabildo y asimismo con la obligación precisa de haber de hacer y de ejecutarse en aquellos actos que el señor Presidente le mandare según juzgare conveniente y necesario en atención de no tener dicha Capellanía por supernumeraria particular y no como más largamente se contiene en el auto de su elección».

Documento 9: Exigencia de devolución de partituras e instrumentos (Acta del 4 de noviembre de 1740)

«Deliberaron que Gerónimo Gil, en cuyo poder paran los papeles e instrumentos pertenecientes al Priorato fundado en la Capilla de San Salvador de esta Catedral, como heredero que es del Prior Gil, su hermano ya difunto, les entregue a mosén Javier Comba, secretario del Ilustre Cabildo, y que queden en su custodia, como los demás pertenecientes a otros Beneficios, y asimismo la arca con su llave donde se hallan los ornamentos con su cáliz y patena, pertenecientes a los Priores que por tiempo fueren, y que si mosén Joseph Montero, bajonista ecónomo nombrado por el señor Vicario General, para la administración, cobranza y pago de los censos y derechos pertenecientes a las administraciones anexas al Priorato, durante la ausencia del actual Prior necesitare de algunos instrumentos se los deba franquear dicho mosén Comba dejando su recibo».

Documento 10: Multa al tenor Lorenzo Heredia (Acta del 8 de enero de 1741)

«Habiendo instado al señor Deán el señor Arcediano Benlloch para que convocara a Cabildo, el dicho señor Benlloch hizo relación como a tiempo antes de entrar en el coro, hallándose en el claustro el 
señor canónigo Ortells y el señor canónigo Bach, hablando con mosén Vicente Fabra, sochantre, en que le prevenían no se llevara el coro con tanta velocidad, como se llevaba por haberse notado aún en los semidobles ser excesiva la velocidad en las misas cantadas, y habiendo notado esta advertencia mosén Lorenzo Heredia, Chantre, alborotando éste el claustro, y a vista de algunos eclesiásticos que pudieron advertir lo desentonado y descompuesto con que se explicaba el dicho mosén Heredia, prorrumpió éste contra el Cabildo con palabras de mucha audacia y poco respeto hacia él, pues con la misma desanteción se explicó por la mañana en el coro contra algunos capitulares a tiempo que se cantaba la misa de pago, de forma que muchos de los residentes notaron su audacia y aún oyeron sus palabras de poco respeto hacia los dichos Capítulares; por lo que deseando dichos Señores contener los excesos y libertades del referido mosén Heredia para en adelante y castigar lo mal hecho de aquel, deliberaron se le multe en $101 \mathrm{~L}$ [ibras], aplicándolas desde luego para gastos del órgano».

Documento 11: Petición de clemencia para Lorenzo Heredia (Acta del 11 de enero de 1741) «Señores Deán, Benlloch, Lloréns, Montero, Feliú, Bach, García, Besols, Albert, Ortells. Habiendo su Ilustrísima mediado con el Cabildo, por medio de pecado que pasó a él, en su nombre el señor Canónigo Feliú para que el Ilustre Cabildo si le pareciera bien, minorara la multa que con deliberación del día 9 se le impuso a mosén Lorenzo Heredia, Chantre, por las causas allí expresadas, y teniendo presente dichos señores los multiplicados motivos que tienen para complacer en un todo a su Ilustrísima, deliberaron que suba el dicho señor Canónigo Feliú al señor Obispo, y ponga en sus manos, y advirtió la referida multa para que su Ilustrísima disponga como bien visto le sea».

Documento 12: Concesión al maestro de capilla, José Conejos (Acta del 18 de febrero de 1741) «Habiéndose hecho la gracia a mosén Joseph Conejos, Maestro de Capilla, contenida en la deliberación en el día 8 de febrero del presente año, y habiendo posteriormente entendido dicho mosén Conejos que por el tiempo se podía agregar a la Capilla de la comunión la de todos los Santos, y que con este medio no lograría el fin que representó al Ilustre Cabildo en la obra que deseaba hacer, representó nuevamente a dichos señores el deseo [que] tenía de que se le asignara la Capilla de Santa Cruz, vulgarmente llamada de la paz, constituida en el Claustro de esta Santa Iglesia para hacer en ella la obra que deseaba hacer en la de todos Santos, deseando en el Altar la Santa Cruz, bajo cuya invocación se halla constituida dicha Capilla; y entendida por dichos señores la referida súplica: Deliberaron se le haga la gracia a dicho Maestro con las referidas circunstancias».

Documento 13: Obra de José Conejos en una capilla de la catedral (Acta del 9 de julio de 1741) «Asimismo, considerando que la obra que mosén Joseph Conejos quería hacer en la Capilla de la Paz con permiso que se le dio para ello, que el Ilustre Cabildo en la deliberación del día 18 de febrero del corriente año había de quedar muy ahogada por la oscuridad de dicha Capilla, y que para el lucimiento de la obra era mas proporcionada la Capilla de San Miguel y todos Santos, deliberaron que, sin embargo del permiso dado en la citada deliberación del día 18 de febrero pasado, se le dé recado para si quisiere hacer la referida obra el dicho mosén Joseph Conejos en la Capilla de San Miguel y todos Santos, lo pueda ejecutar».

Documento 14: Informe de José Conejos y del domero sobre dos opositores a sochantre y aceptación de dicho informe por parte del Cabildo (Acta del 9 de diciembre de 1741)

«Por cuanto por relación que con fecha del día 17 nos han hecho mosén Joseph Conejos, Maestro de Capilla de esta Santa Iglesia, y mosén Joaquín Gómez, Domero de la misma, examinadores nombrados para el concurso de la Capellanía de sochantre, en virtud de nuestra deliberación de nueve de los corrien- 
tes, cuya relación inseriptis es del tenor siguiente: obedeciendo el precepto del muy ilustre cabildo de esta Santa Iglesia, hemos examinado a Miguel Sanz, capiscol de la Iglesia Parroquial de Santa Cruz de Valencia, y a Joaquín Royo, únicos opuestos al obtento de la capellanía de sochantre, vacante en dicha Santa Iglesia, arreglándonos al tenor del edicto que se publicó, y cualidades que en los pretendientes deben concurrir para el desempeño de las obligaciones, que en fuerza del edicto y costumbre de la Iglesia van anexas a dicha capellanía; y somos de dictamen que ni uno ni otro tienen la suficiencia necesaria para el obtento de dicha capellanía y cumplimiento de sus obligaciones; y en descargo de nuestra así lo sentimos, y firmamos como tales examinadores sujetando nuestro juicio al superior de dicho muy ilustre cabildo en Segorbe y diciembre a 17 de 1741: mosén Joseph Conejos, Maestro de Capilla y mosén Joaquín Gómez, Domero: consta que ninguno de los opuestos tiene las cualidades necesarias para el cumplimiento de las obligaciones, que en fuerza del edicto publicado y costumbre de esta Santa Iglesia, y por lo consiguiente ni derecho alguno para su obtento en fuerza de su concurso u oposición. Por tanto dictándolo así la justicia y el buen Gobierno de la Iglesia nos conformamos con el juicio de los referidos examinadores, declarando quedar nuestro cabildo con absoluta libertad de poder nombrar o elegir a cualquier otro sujeto que tenga la suficiencia necesaria para obtento de dicha capellanía y desempeño de sus obligaciones».

Documento 15: Multa a músicos de la capilla (Acta del 1 de agosto de 1742)

«Siendo costumbre inconclusa en esta Santa Iglesia observada entre los Músicos y Maestro de Capilla, que tan dados aquéllos, por éste en músicas y fiestas de fuera la Iglesia le obedezcan asistiendo a dichas funciones, habiendo acontecido la festividad de San Ignacio de Loyola en el colegio de la compañía de esta Ciudad y convocado el Maestro de Capilla para que junto con los músicos asistiese a dicha función, tan dados éstos, se resistieron y dejaron de ir mosén Lorenzo Heredia, mosén Joaquín Gómez y mosén Bautista Ripoll, por lo que atendiendo dicho muy Ilustre Cabildo la publicidad y escándalo, ya por asistir mucho concurso, ya por cantar la Misa Capítular y reconocer frustráneas sus pretensiones, si acaso las tuvieren, por haberse todo podido componer alegando sus quejas al muy Ilustre Cabildo, se deliberó que para que en adelante no sucediesen semejantes atentados, se les multase en treinta reales a cada uno, quitándoles la distribución que ganasen en los días que asistieran al coro hasta completar los dichos treinta reales, entendiéndose irremisible dicha multa».

Documento 16: Actuaciones de la capilla en los barrios de Segorbe (Acta del 10 de septiembre de 1742)

«Por cuanto en las fiestas que hacen los barrios de esta ciudad a sus patronos o de especial devoción se ha empezado a introducir la novedad de no llamar la Capilla de Música de esta Santa Iglesia con el pretexto de la pobreza de los vecinos, para con esta circunstancia justificar con los señores capitulares a quienes convidan para la misa la otra de la falta del mayor obsequio al principal objeto de la fiesta, culto y más decencia; siendo así, que se ha experimentado que no les faltan efectos para dar otras costosas diversiones y que por su gasto exceden en mucho al que debe llevar dicha Capilla por su asistencia: por tanto deliberaron que ninguno de los capitulares admita misa alguna en las sobredichas funciones de fiestas de barrios, menos que constándole previamente estar convocada la Capilla para su asistencia, y que esta deliberación se haga saber por el infraescrito secretario a los demás señores ausentes para su observancia».

Documento 17: Condonación de una multa impuesta a tres miembros de la capilla (Acta del 15 de diciembre de 1742)

«Habiendo mosén Juan Bautista Ripoll presentado męmorial en el que suplicaba se le condonase la multa que se le puso por no haber querido asistir a la festividad de San Ignacio de Loyola, a la que debía asistir por haber sido celebrado dicho día con la música de la Iglesia, como consta de otra deliberación, y 
en conformidad de esta súplica, habiendo incurrido en la misma multa mosén Lorenza Heredia y mosén Joaquín Gómez, y suplicado el señor García como principal agraviado se les perdonase la multa a los tres arriba dichos, se condescendió a su súplica y se deliberó se les quitara la marca».

Documento 18: Ampliación de estudios musicales del acólito José Gil (Acta del 15 de diciembre de 1742)

«Asimismo: Habiendo pedido Joseph Gil, acólito de coro, al Cabildo licencia para irse a Valencia, a fin de adelantarse en sus estudios, se le concedió, y se deliberó se le dieran 5 L[ibras] de la administración de prepositura para gastos al viaje. Asimismo, en conformidad de lo pedido por Joseph Gil, suplicó Atanasio Andreu se le tuviera presente para ocupar dicho empleo de acólito de coro, en el caso que se ausentase dicho Joseph Gil y se deliberó sustituyese dicho empleo en caso de que dicho Joseph Gil se ausentase, antes de hacer elección del mismo».

Documento 19: Cuestiones relacionadas con el archivo, con la repetición de obras y con el texto de los villancicos (Acta del 2 de enero de 1744)

«Atendiendo a que en esta Santa Iglesia se conservan diferentes papeles de composiciones de músicas, correspondientes a las festividades, sus circunstancias y tiempos, de todo lo cual hay inventario, deliberaron que se reconozca éste y se vea si están o no otras músicas, y que las que faltasen se recojan los papeles, pasándose todos a otro de los armarios del archivo, que están en el ramo de su escalera, y que en ésto entiendan los señores Tesorero Besols y Albert. Asimismo que respecto de que la repetición de cantarse una misma música no sirve para el adelantamiento ni lucimiento de la Capilla, ni es lo mejor para la devoción que suele exitarse con la variedad, que se echa menos en las músicas de esta Santa Iglesia; que dichos señores entiendan en ordenarle al Maestro de Capilla actual y que por tiempo fuere, qué músicas se hayan de cantar de las que hoy hay en la Iglesia u otras que trajeron de fuera, y que dicho Maestro haya precisamente de obedecer a dos de dichos señores pues en cuanto a dicho punto y demás conexos les tranfiere el Cabildo toda la autoridad necesaria. Asimismo que siendo razón que la letra de los Villancicos de Navidad se examine por su Ilustrísima y por el Ilustre Cabildo o señores nombrados como hoy se acostumbra, y no a punto crudo como hoy se hace, después de la composición y prueba, sino antes de uno y otro; que se ejecute así por dicho Maestro, entregando a su Ilustrísima y a dichos dos señores copias de dicha letra antes de la composición y obteniendo para ésta la aprobación de dicha letra respectivamente».

Documento 20: Obligación de los músicos de asistir a los maitines (Acta del 1 de febrero de 1745$)$

«Considerando dichos señores la grave obligación que hay de cantar en el debido modo en el coro, [y] habiendo advertido que en los días que se celebran maitines, apenas hay quien sepa responder al invitatorio; deliberaron que se les advirtiera a todos los músicos que deban éstos asistir mientras se canta el invitatorio para poder responder alternativamente con los chantres sin que les sufrague a los dichos la facultad que les da el sínodo de poder entrar concluido el invitatorio».

Documento 21: Prohibición a los músicos de la capilla de actuaciones extracatedralicias (Acta del 4 de mayo de 1745)

«A ocasión de haber llegado a oídos del muy ilustre Cabildo cómo algunos de los músicos asisten en muchas funciones de algunas Iglesias de esta ciudad y otras en rosarios por las calles, considerando que por dichos actos se les echa a perder la voz y la salud, de lo cual resulta el no poder acudir a su principal obligación, que es cantar en esta Santa Iglesia, contemplando cuán sobre mayor es dicha obligación, deli- 
beraron, que no puedan asistir y acudir a cantar en función alguna fuera de Catedral, a exepción de cuando asiste en alguna de ellas la capilla, y ejecutando lo contrario serán multados en 10 L[ibras]».

Documento 22: José Gil sustituye al maestro de capilla, José Conejos, en la enseñanza de los infantes (Acta del 9 de agosto de 1745)

«A ocasión de haber expuesto mosén Joseph Conejos, Maestro de Capilla de esta Santa Iglesia, por su memorial en dicho día, encontrase imposibilitado para el cumplimiento de su obligación en la enseñanza de los Infantes y otras de su cargo; considerando dichos Señores ser circunstancia necesaria el buscar sujeto benemérito para el total régimen de dicha Capilla; se deliberó, nemine discrepante, que a Joseph Gil se nombrara para el fin de sustituir en dicho magisterio durante la voluntad del ilustre Cabildo, viniendo bien en ello dicho Gil, y habiendo éste admitido dicha sustitución. Por deliberación del mismo día se le admitió a las distribuciones, las que para lucrarlas necesitara de residir en el coro; y asimismo se le admitió a las músicas, entendiéndose que ganara la porción que ganan otros músicos y la media porción que ganaba el Maestro de Capilla, quedando el dicho con la obligación de regentar la Capilla, componer y enseñar a los Infantes a contentamiento del ilustre Cabildo y durante la voluntad de éste».

Documento 23: Cuestiones relativas al testamento de José Conejos

(Acta del 8 de agosto de 1755)

«Visto el memorial que mosén Joaquín Gómez, Domero de esta Santa Iglesia y mosén Joseph Martín, Capellán de Santuario de Nuestra Señora de la Cueva Santa, presentaron memorial en el que manifestaron ser albaceas y ejecutores testamentarios de m. Joseph Conejos, Maestro de Capilla que fue de esta santa Iglesia y suplicaron que deseaban poner en ejecución lo dispuesto por dicho señor Conejos, habiendo advertido que dicho mosén Conejos en su testamento, que los dichos albaceas presentaron, dispone que el producto de dichos bienes se convierta en fundar y hacer celebrar cinco misas perpetuas cantadas [en] modo recitativo en la capilla ahora de San José y San Blas del claustro de esta Santa Iglesia, siendo esta disposición como la que expresa acerca de la almoneda de dichos sus bienes perjudicial al Ilustre Cabildo y sus derechos, por lo mismo sin embargo que los dichos señores solicitaron por dicho memorial que el Ilustre Cabildo diera su permiso y expreso consentimiento para poder poner en práctica lo marcado en dicho testamento, se determinó por varias razones que se tuvieran presentes que no se permitiese el cumplimiento de dicha disposición, no se diese para ello el consentimiento por no ser admisible ninguno de los términos con que lo expresa el testador y que se decrete al dicho memorial en estos mismos términos».

(Acta del 9 de agosto de 1755)

«... en conformidad de haberse decretado en el día que precede que no se permitiese el cumplimiento de la disposición de M. Joseph Conejos ni que se diese para ello el consentimiento, y de tener en este caso réplica o contradicción, facultades [de] mosén Joaquín Gómez y mosén Jospeh Marín, sus albaceas, dadas por el mismo testador, como se deja ver en otra de las cláusulas de dicho testamento, usando de ellas pasaron a la parte de acordárselas al señor ordinario, presentándola para ello al dicho testamento y al mismo tiempo le manifestaron que el Ilustre Cabildo no admitió dicha obra pía en los términos que expresó el testador, cuyo memorial y decreto representaron, y por otro le manifestaron era llegado el caso de declarar la voluntad, y era: que del producto de los bienes dejados por el referido mosén Conejos en lugar de las cinco misas cantadas [en] modo recitativo se celebrase en el altar mayor de dicha Santa Iglesia todos los años en el día de San Joaquín una Misa canonical solemne, concluida la hora, con todo lo demás que consta en dicho memorial, y que respecto que en dicha declaración había alguna variación aunque accidental por querer que las cinco misas cantadas [en] modo recitativo se convirtieran en una canta- 
da de mayor solemnidad, suplicaron a dicho Señor ordinario diese su aprobación y correspondiente decreto sobre lo dicho...».

Documento 24: Exigencia de regreso a un miembro de la capilla (Acta del 1 de febrero de 1746)

«Por cuanto el Ilustre Cabildo dio licencia a Atanasio Andréu, mozo de coro, para dejar otro en su lugar por el tiempo en qu estuviese en Valencia, donde bajó, a fin de adiestrarse en los instrumentos que por el Ilustre Cabildo se le significó, como más largamente consta por otra; considerando haberse aplicado y adelantado en los instrumentos que se le previno; por tanto, y por considerar ser preciso no diferir el proveer dicha capellanía por motivo de hacer falta quien taña la chirimía, deliberaron se le escribiera a dicho Atanasio Andréu, estuviera en ésta para el día de la Purísima, para quedarse en ésta; y habiéndose pensado en exigirle la capellanía de chirimía a su favor, interim no se ejecute, se acordó que residiendo personalmente se le dieran las distribuciones, mejoras, músicas, etc.».

Documento 25: Prohibición de asistencia a una procesión a los miembros de la capilla (Acta del 2 de abril de 1746)

«Por los justos motivos que se tuvieron presentes, deliberaron que la Capilla de la música de esta Santa Iglesia, ni como tal ni como tales particulares no vayan ni asistan en el día de jueves santo por la tarde inmediata siguiente en la procesión que en la de dicho día se celebra en la villa de Altura, con apercibimiento de 10 L[ibras] de multa, que en el caso de contravención se exigirán respectivamente de los individuos que la componen según proceda de justicia, y que para su puntual observancia se haga saber esta deliberación a mosén Joseph Gil, regente de dicha Capilla para que lo ponga en noticia de ésta».

Documento 26: Advertencia del Cabildo al responsable de las campanas (Acta del 2 de abril de 1746)

«Asimismo: que se prevenga a mosén Joseph Campos, a cuyo cargo está el gobierno del campanario por su capellanía, presente papel a nuestro Cabildo con razón individual del salario que da al campananero ordinario secular que le sirve; qué número de dias será el de vuelo de campanas en cada un año poco más o menos, qué asistentes llama para dicho fin en tales días, y cuánto les suele dar a cada uno por su trabajo».

\section{Documento 27: Actos en honor del nuevo rey Fernando VI}

(Acta del 26 de agosto de 1746)

«Por cuanto la Majestad del Rey nuestro Señor, el Señor don Fernando VI (Dios le guarde), exaltado al trono de esta monarquía y deseoso de conseguir el acierto en su gobierno, que principalmente depende de la Divina asistencia, y considerando que las rogativas a Dios Nuestro Señor son el medio para conseguirla, mandó a este su Cabildo se ejecutasen en esta Santa Iglesia, por su Real Carta del tenor siguiente: Inseratur: y deseando nuestro Cabildo cumplir con la obligación en cuanto mira al Real Servicio y nada menos acreditar su celo, y cooperar, como por todos los respetos debe, a las tan rectas y piadosas intenciones de su Majestad, siguiendo la costumbre y práctica de esta Santa Iglesia sobre rogativas en casos de esta similitud, como son deber en su libro de memorias, deliberaron las siguientes:

Primeramente que desde luego se diga en todas las misas la oración pro Rege, y que a ese fin se fije papel en el coro al pie del Santo Cristo, para que por todos así se ejecute: que haya tres días de rogativas, que se empezarán en ese día 29 del presente mes, y se concluirán en el 31 del mismo: que en cada uno de dichos días se celebre una Misa solemne Canonical post Nonam con música por dicha intención, 
estando expuesto el santísimo sacramento los tres días durante todos los divinos oficios de mañana y tarde, siendo las dos primeras Misas del sacramento y la tercera de Beata María, y todas con la oración pro Rege; que por la tarde de cada uno de dichos días acudan las comunidades mendicantes a hacer también sus rogativas como lo acostumbran en semejantes casos, cada una por su antigüedad, y que a este fín se les envíe recado de convite según costumbre por un subsíndico; pero con la prevención que lleve el recado por escrito, y que vaya acompañado de nuestro escribano, para que en todo tiempo pueda dar testimonio de continuarse por nuestro Cabildo por este acto la posesión inmemorial en que se halla, por convenir así a su derecho, y dictarlo al sistema de las presentes diferencias con su Ilustrísima, que concluidas respectivamente las rogativas de cada comunidad, entre la Iglesia a hacer por su parte la suya, que se reducirá en cada día a cantarse la letanía mayor en el Presbiterio, con las preces del caso que se resolverán con consulta del Maestro de Ceremonias, acompañando la música, concluyéndose así la función; y finalmente que para su mayor solemnidad, edificación, y lucimiento de ella se dé recado de convite a su Ilustrísima por el señor Síndico capitular, y por el mismo a él de la ilustre ciudad para que lo pase a ésta para el fin de la asistencia y que todo lo que se ejecutase se continue en el libro de memorias».

(Acta del 17 de septiembre de 1746)

«Atendiendo la ilustre Ciudad de Segorbe a que en la de Valencia se habían ejecutado por estas grandes fiestas en testimonio de su fidelidad y gozo por la exaltación al trono de nuestro Rey el Señor don Fernando Sexto (Dios le guarde) y que era razón que en la presente se hicieran todas las que arbitrare la posibilidad como lo resolvió, y que por su síndico diera recado a nuestro Cabildo, rogando a éste la acompañara con lumenarias en la torre y en las funciones de Iglesia, y señaladamente en la de procesión general, y en la de Te Deum laudamus si les parecía resolverlo, ofreciéndose por su parte a convidar a las comunidades religiosas para la asistencia en ambos actos, pero representando al mismo tiempo la imposibilidad con que se hallaba de costear la distribución de ellos por el concurso y embargo en que tenía los efectos de sus propios; como así nos lo hizo presente nuestro sindico mediante el recado que le dio el de la Ciudad: por tanto y deseando el Ilustre Cabildo de nuevo acreditar con tan plausible motivo su celo y fidelidad a su Rey y Señor como manifestar el gozo con que le tiene su exaltación al trono, y conformándose también con el ejemplar de Valencia, que se redujo a una Misa solemne de gracias, y procesión general; deliberaron que en los tres días de lumenarias acompañe la torre con luces duplicadas sobre las que ordinariamente se acostumbran, en los días 23,24 y 25 y que en éste se cante una misa solemne de gracias post Nonam por dicha intención, y por la tarde del mismo día la procesión general, trayéndose Nuestra Señora de Gracia a la Iglesia, para toda la función, y en la procesión también la reliquia de nuestro Patrón, el Señor San Vicente Ferrer, y haciéndose estación entrando de paso en el convento de San Pablo, y repitiéndose en la Capilla del Santo en el claustro; continuándose en el libro de memorias todo lo que se ejecutase en virtud de esta deliberación».

Documento 28: Beneficio en favor de José Gil Pérez (Acta del 16 de agosto de 1754)

«Habiéndosele a mosén Joseph Gil presentado la capellanía vacante de Maestro de la Capilla, y llegado a dudarse qué silla era la suya en el coro, si la inmediata después de los oficios o después del beneficiado llamado Prior, se hizo la propuesta por el señor Deán para que se tomara por el Ilustre Cabildo determinación sobre ello, y teniendo presente que mosén Joseph Conejos, inmediato antecesor en la Capellanía que posee mosén Joseph, se presidió a mosén Joseph Gil, beneficiado, en el beneficio de Prior; se determinó que supuesto que este era el último estado, que la posesión estaba a favor del Maestro de Capilla último poseedor, que la misma se continuase en la actual, y que a Miguel Martín Prior, se le previniese esto mismo, y que el ilustre Cabildo tendrá a bien que se le comunique cualquier pretensión si la tuvie- 
re en semejante asunto, pero al mismo tiempo se determinó que entretanto se esté a lo deliberado por el ilustre Cabildo sin perjudicar los derechos que pudiera tener y que el señor Deán le dé este recado».

Documento 29: Discusión en torno al Beneficio de José Gil Pérez (Acta del 23 de agosto de 1754)

«Sin embargo de lo deliberado en Cabildo inmediato pasado, porque siempre no obstante lo que allí se expresa podía llegar el caso de dudarse si mosén Joseph Conejos precedió a mosén Joseph Gil, Prior, por haber aquél tomado antes punto en el coro que éste, como le tomó o por razón de su Capellanía, deseando no perjudicar alguno de los dichos en su derecho sino dejarle a cada uno en el que le competa, pareció convenientísimo apurar más la verdad, y habiéndose averiguado que mosén Miguel Monchiu y Panzano, Maestro de Capilla tomó punto de residencia el año 1664 y mosén Joseph Pastor, Prior en el de 1657, y que sin embargo de ello, precedió al otro Prior el expresado Maestro de Capilla, y asimismo que de entonces acá a todos los Maestros de Capilla se les ha continuado esta posesión, en vista de ello, se determinó nuevamente que sin perjuicio de los derechos que pueda tener mosén Miguel Martín, Prior, le preceda al otro el Maestro de Capilla; y respecto que el dicho mosén Martín puso en el día de hoy memorial en el que suplicó al Ilustre Cabildo que se le concedieran 15 días de tiempo para ver un libro que tiene en su poder de la institución de dicho Priorato, a fin de averiguar y certificarse si había alguna razón en que pudiese fundar que debía preceder al Maestro de Capilla, se resolvió que practicase éstas y otras diligencias si le pareciere, que estuviese cierto que el ilustre Cabildo en todo tiempo le oirá en lo que propusiere el dicho Prior, supuesto que su ánimo no es otro que dar a cada uno lo que le compete, mas que entretanto se esté a lo deliberado y que el Maestro le deba preceder sin perjuicio de sus derechos, pues todos se los saltará el Ilustre Cabildo en caso de hacer ver que le competen lo que se deliberó, y que el señor Deán le dé recado al tenor de esta deliberación». ${ }^{89}$

Documento 30: Reproches del Cabildo y multa a José Gil Pérez (Acta del 8 de julio de

«Por cuanto en este día presentó mosén Joseph Gíl, Maestro de Capilla, un memorial no correspondiente al autorizado de este muy ilustre Cabildo por contener cláusulas indecorosas contra su presidente pidiendo la gracia de relación de la multa de 3 libras que dicho Presidente le había puesto por haber faltado dos infantillos a las Vísperas de día 5, en las que entraron concluido el primer salmo excusándose los dichos al cargo que el señor Presidente les hizo con que su maestro les había ocupado, y que siendo de la autoridad dicho Maestro mandar en dichos infantes sin licencia expresa del muy ilustre Cabildo o su Presidente, es sólo el cuidado propio de su ministerio en la educación y cumplimiento de su obligación en la enseñanza de aquéllos, en la que por haberse observado ser omiso dicho Maestro, y no haber bastado las advertencias del señor Deán, de dicho señor Belloch como Presidente y aún también del señor Ronda de orden del muy ilustre Cabildo; deliberaron los sobredichos señores de devolverle dicho su memorial sin relevarle de la multa impuesta por dicho señor Presidente y con apercibimiento, cuidándose en adelante en el cumplimiento de su obligación, y suplicase en términos correspondientes. Asimismo teniendo presente el muy ilustre Cabildo que el ejercicio de dicho Maestro de capilla en el coro es el cuidado de la Capilla y mayormente el de los infantillos, deliberó tenga su asiento en dicho coro en la silla colateral a la del Maestro de ceremonias que es en el coro de abajo la inmediata a la de los chantres, precediendo el dicho Maestro en las demás funciones de fuera de coro y las de música a todos los beneficiados y capellanes de forma que tendrá su lugar inmediato a los cuatro oficios, quedando así zanjada la pretensión del Prior de San Salvador, y concordados en esta tarde las deliberaciones que en este asunto quedan establecidas».

89. ACS, 23-8-1754. 


\title{
APÉNDICE II
}

\section{Documentación}

\author{
(Actas Capitulares de la Catedral de Orihuela)
}

Documento 1: Nombramiento de Joaquín López como maestro de capilla de la Catedral de Orihuela en sustitución de José Martínez Lafós

(Vol. 42, Acta del 15 de abril de 1785)

«Habiendo precedido convocación especial para traer la consulta, terna y propuesta a su Majestad de los opositores a la media ración de esta santa Iglesia afecta al magisterio de capilla vacante por muerte de don José Martínez Lafós y habiendo votado por votos secretos en la forma acostumbrada para el primer lugar de la terna resultó que don Ramón Ferrañac tuvo de 24 votos que eran 21, por lo que quedó elegido para el primer lugar de la terna; y habiéndose precedido a votar en el mismo modo para el segundo lugar de ella, tuvo don Joaquín López 19 votos, por cuya razón quedó electo para el segundo lugar de la expresada terna y finalmente habiéndose votado en la misma forma para el tercer lugar de la terna, consulta y propuesta a su Majestad: de las cuales votadas resultó que el susodicho don Ramón Ferreñac tuvo cinco votos para el segundo lugar de la expresada terna el nominado don Joaquín López sacó tres votos para el primer lugar y seis para el tercero».

(Vol. 42, Acta del 18 de abril de 1785)

«Habiéndose precedido convocación especial, Decreverunt: que la copia de las censuras remitida por el ilustrísimo señor Obispo de los opositores a la media ración de esta santa Iglesia afecta al magisterio de capilla quede inserte en el Cabildo de este día para que de ella se puedan librar los testimonios que fueren necesarios para remitir juntamente con la terna a la real Cámara; y dicha censura a la letra es como sigue: Los infrafirmados examinadores nombrados por el ilustrísimo señor Obispo de Orihuela para el concurso de oposiciones a las dos medias raciones vacantes en la Santa Iglesia Catedral de dicha ciudad, afectos al Magisterio de capilla y a la voz de bajo de primer coro, cuyo encargo tenemos aceptado, y jurado, hemos asistido a todos los catos de las oposiciones hechas a la primera de dichas piezas (a que únicamente ha habido pretendientes), celebrados desde el día 18 hasta el 24, ambos inclusiva de próximo pasado mes de febrero y habiendo hecho reflexión sobre todos ellos, y respectivo desempeño de los opositores, los aprobamos y demos por bien hechas las oposiciones de don Ramón Ferreñac, según el juicio que hemos formado tiene habilidad superior; el expresado don Joaquín López la tiene más que mediana y el contenido don José Ferrer tiene buena suficiencia y disposición para poder ser muy útil. Así lo sentimos, sin respetos humanos, ceñidos a la religión del juramento que hemos hecho y lo firmamos en la Villa de Elche a 20 de marzo de 1785: Mosén Jacinto Redón, maestro de capilla, mosén Vicente Claver».

(Vol. 42, Acta del 19 de septiembre de 1785)

«Vista la carta de don Joaquín López en que participa al ilustre Cabíldo haberle agraciado Su Majestad con la media ración de esta Santa Iglesia afecta al magisterio de capilla, Decreverunt: que se le responda dándole su enhorabuena. Decreverunt: que se dé a don Ramón Ferreñac, opositor que ha sido al magisterio de capilla de esta santa Iglesia el certificado que pide». 
(Vol. 42, Acta del 3 de octubre de 1785)

«En este día por parte de don Joaquín López se presentó la real cédula de su majestad de la media ración de esta santa Iglesia afecta al magisterio de capilla que es una de las que se ha divido la capellanía real que obtenía don José M. Lafós, expedida a su favor y las letras de colación y demitiendo possesionem de caballero provisor de este obispado a efecto de que se le ponga en ella; y el señor Doctor don Pedro Albornoz y Celerián, dignidad de chantre y canónigo de dicha Santa Iglesia y Presidente, recibió dichos despachos con la debida veneración y respeto, y poniéndoselos sobre su cabeza y los cometió para su examen y reconocimiento».

(Vol. 42, Acta del 7 de octubre de 1785)

«Habiendo precedido convocación especial y oida la relación del señor Miravete sobre la real cédula de su Majestad y demás despachos de la media ración de esta santa Iglesia afecta al magisterio de capilla, que es una de las dos en que se ha dividido la capellanía real que obtenían don José Martínez Lafós, expedidos en favor de don Joaquín López por cuya relación ha constado estar dichos despachos en debida forma sin oponerse a los estatutos y loables costumbres de dicha Santa Iglesia: Decreverunt: se dé al expresado Joaquín Lopéz la posesión de la referida media ración, para cuyo efecto habiendo entrado en la sala capitular y hecho y prestado el juramento acostumbrado en manos y poder del señor doctor don Pedro Albornoz y Cebrián, dignidad de chantre y canónigo de la mencionada Santa Iglesia y presidente, se le dieron quieta y pacíficamente sin contradicción de persona alguna en la décima silla del coro bajọ y lado derecho de dicha Santa Iglesia, estándose en él celebrando los divinos oficios, de que recibí auto, siendo testigos don Jaime García, segundo maestro de ceremonias y don Francisco de los Ríos, sacristán mayor de la expresada S. I. de Orihuela». 


\section{APÉNDICE III}

\section{Relación de cargos y músicos de la Catedral de Segorbe}

\section{Principales cargos eclesiásticos}

Primeras dignidades:

Deán, Arcediano, Chantre y Tesorero

Antiguos Oficios:

Arcipreste, Obrero, Escolastre, Enfermero y Limosnero

Canonjías de Oficio:

Lectoral, Doctoral, Penitenciario y Magistral

Otras canonjías:

Prepositura, Canonjía de San Jaime, y Canonjía de la Inquisición.

Beneficiados y otros servidores:

Prior, Maestro de Gramática y Artes liberales, Maestro de Canto (Con el tiempo, su denominación será la de Maestro de Capilla), Médico del obispo y cabildo y de los pobres, Capellán misalbero, Diaconil, Subdiaconil, Sacristanes, Apuntador, Organista, Manchador, Pertiguero, Maestro de Ceremonias, Notario del cabildo, Otro maestro de ceremonias, Sochantre o Cantor, Ayudante del sacristán, Segundo diaconil, Segundo subdiaconil, Ministro de báculo, Ministro de mitra y Niños de coro. 


\section{Maestros de Capilla}

Siglo XVI:

Francisco Juan Azín

Nicolás Mariner

Siglo XVII:

Marcello Settimio

José Selma

Miguel Monchiu Panzano

Mateo Peñalba

Siglo XVIII:

Onofre Molina

José Conejos Ortells

José Gil Pérez

Francisco Vives

Vicente Olmos

Joaquín López González

José Morata García

José Gil

Siglo XIX:

Francisco Santafé

Francisco Andreví

Miguel Soriano Morata

Valeriano Lacruz Argenta

Siglo XX:

José Perpiñán

Organistas

Siglo XVII:

Severino Franch
Siglo XVIII:

Vicente Franch

Joaquín Perales

José Casaña

Rosendo Tortajada

Siglo XIX:

Vicente Pina

Mateo Lorente

\section{Cantores}

Siglo XVIII:

Ambrosio Gómez (Contralto)

Lorenzo Juan (Contralto)

Vicente Selma

Lorenzo Heredia

Vicente Fabra (Tenor)

Joaquín Gómez

Bautista Ripoll

Joaquín Gil (Tenor)

\section{Instrumentistas}

Siglo XVIII:

Baltasar Flor

Antonio Díaz

Jorge Morante (Bajón)

Joseph Montero (Bajón)

Ignacio Fulla (Bajón)

Atanasio Andréu (Chirimía) 